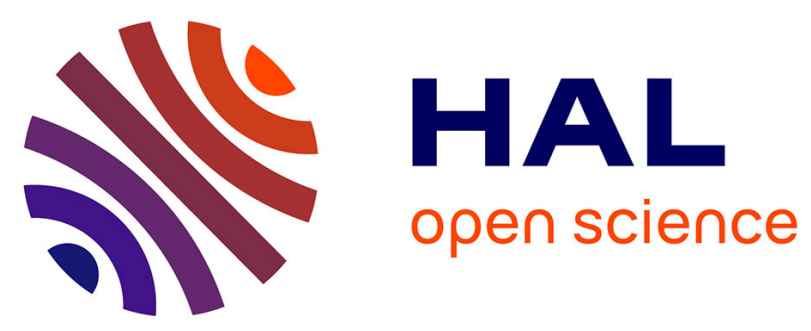

\title{
Extension of the group contribution NRTL-PRA EoS for the modeling of mixtures containing light gases and alcohols with water and salts
}

\author{
Evelyne Neau, Christophe Nicolas, Laurent Avaullée
}

\section{To cite this version:}

Evelyne Neau, Christophe Nicolas, Laurent Avaullée. Extension of the group contribution NRTL-PRA EoS for the modeling of mixtures containing light gases and alcohols with water and salts. Fluid Phase Equilibria, 2018, 458, pp.194-210. 10.1016/j.fluid.2017.09.028 . hal-01703014

\author{
HAL Id: hal-01703014 \\ https://hal.science/hal-01703014
}

Submitted on 12 Feb 2018

HAL is a multi-disciplinary open access archive for the deposit and dissemination of scientific research documents, whether they are published or not. The documents may come from teaching and research institutions in France or abroad, or from public or private research centers.
L'archive ouverte pluridisciplinaire HAL, est destinée au dépôt et à la diffusion de documents scientifiques de niveau recherche, publiés ou non, émanant des établissements d'enseignement et de recherche français ou étrangers, des laboratoires publics ou privés. 


\title{
Extension of the group contribution NRTL-PRA EoS for the modeling of mixtures containing light gases and alcohols with water and salts
}

\author{
Evelyne Neau $^{\mathrm{a},{ }^{*}}$, Christophe Nicolas $^{\mathrm{b}}$ and Laurent Avaullée ${ }^{\mathrm{c}}$ \\ ${ }^{a}$ Aix Marseille Univ., CNRS, Centrale Marseille, M2P2, Marseille, France \\ ${ }^{\mathrm{b}}$ MIO (Mediterranean Institute of Oceanography) UMR 7294, Aix Marseille Université, France \\ ${ }^{\mathrm{c}}$ TOTAL S.A. - CSTJF, Av. Larribau, Pau, France
}

\begin{abstract}
The offshore exploitation of petroleum fluids in normal conditions of pressure and temperature of transport and in presence of salt water is concerned with the prevention of gas hydrate formation, generally thanks to continuous injection of inhibitors, or punctual injection of methanol in start-up and shut-down operations. Hence, models of interest should provide both, satisfactory phase equilibrium estimations of hydrocarbon and alcohol mixtures with water and reliable predictions of their behavior in presence of salts.

In this work, the NRTL-PRA EoS is extended to the prediction of phase equilibria in mixtures containing strong electrolytes. The proposed model assumes that the $a$ and $b$ parameters of the cubic EoS only depend on the solvent mole fractions (salt-free), while the $g_{E o S}^{E}$ excess Gibbs energy describes all the interactions between solvents and ions with only two contributions: the SMR term, specific of "Short and Middle Range" interactions between solvents and salts, and the $L R$ relation proposed by Pitzer-Debye-Hückel, for the description of "Long Range" electrostatic interactions. The proposed electrolyte version of the NRTL-PRA model was successfully extended to the modeling of phase behavior of mixtures of light gases at high pressures (methane, carbon dioxide, nitrogen and hydrogen sulfide) and alcohols (methanol, ethanol and 1-propanol) with water and salts (mainly, ternary mixtures containing sodium chloride). As far as possible, results were compared with those provided, for the same systems, by other literature models (cubic Eos, SAFT and CPA equations).

Keywords: Phase equilibria; EoS/G ${ }^{\mathrm{E}}$ approach; NRTL-PRA EoS; Electrolytes; Group contributions.
\end{abstract}

\section{Introduction}

Formation of gas hydrates leading to pipeline plugging risk is a major problem in offshore petroleum exploitations in transport conditions of pressure and temperature. Their apparition being commonly solved by injecting inhibitor, particularly methanol during transient operations of start-up or shut-down of the transport facilities, an accurate prediction of phase equilibria in mixtures containing hydrocarbon and methanol with salt water is of great interest for petroleum industry.

Many models were proposed in literature for this purpose, which all consist in introducing additional terms to account for the presence of salts in aqueous phases. Among them, the most

*corresponding author: evelyne.neau@ univ-amu.fr 
popular derive from the SAFT EoS, such as the ePC-SAFT of Cameretti et al. [1] and SAFT-VRE of Galindo et al. [2], or from the CPA equation, as the eCPA model of Courtial et al. [3]. The extension toward electrolytes mainly consists in introducing a specific term for ions directly in the expression of the global residual Helmholtz energy: $A^{\text {res }}=A_{\text {non ionic }}^{\text {res }}+A_{i o n}^{\text {res }}$, the additional term usually accounts for both "long range" and "middle range" interactions respectively: by means of the DebyeHückel term of Pitzer [4], MSA [5] or SR2 [6] equations and the Born model [7].

Regarding models based on cubic EoS, most of them derive from two possible approaches, all of them assuming that the salt is not present in the vapor phase: the "homogeneous approach" (LIQUAC equation of Yan et al. [8] or PSRK-LIFAC model of Li et al. [9] and VTPR-LIFAC equation of Collinet and Gmehling [10]), where a classical EoS is associated with a specific expression of the excess Gibbs energy $g_{E o S}^{E}$ taking ionic species into account. The second technique, initially proposed by Fürst and Renon [6], is an "intermediate approach" which consists: first, in estimating the compressibility factor $\mathrm{Z}$ (without taking account salts) and then, in introducing the previous additional "long range" and "middle range" interactions in the derived residual Helmholtz energy ( $\mathrm{Vu}$ et al. [11] or Sieder and Maurer [12]); we can only regret that "ionic" interactions are not considered for the estimation of the compressibility factor.

Another approach proposed by Masoudi et al. [13] with cubic EoS assumes that salts are present in all phases; even if this assumption allows much more classical "flash" calculations, it usually leads to hard convergence problems, mainly due to the problematic representation of the "unknown" critical parameters of ions.

The purpose of the present work is to extend the fundamental bases of the NRTL-PRA EoS [14] to the prediction of phase equilibria with mixtures containing strong electrolytes. The proposed model is based on the "homogeneous approach" described previously, assuming also that salts are not present in the vapor phase. The $a$ and $b$ parameters of the cubic EoS only depend on the solvent mole fractions (salt-free), while the $g_{E O S}^{E}$ excess Gibbs energy describes all the interactions between solvents and ions with only two contributions:

- the SMR term, specific of "Short and Middle Range" interactions between solvents and salts, - the $L R$ relation proposed by Pitzer-Debye-Hückel [4] for the description of "Long Range" electrostatic interactions.

The proposed electrolyte version of the NRTL-PRA model was applied to the modeling of light gases at high pressures (methane, carbon dioxide, nitrogen and hydrogen sulfide) and alcohols (methanol, ethanol and 1-propanol) with water and salts (mainly, ternary mixtures containing sodium chloride).As far as possible, results were compared with those provided, for the same systems, by other literature models (cubic Eos, SAFT and CPA equations).

\section{Extension of the NRTL-PRA EoS to mixtures containing electrolytes}

The presence of electrolytes in a mixture does not only require a new modeling of the $g_{E o S}^{E}$ excess Gibbs energy, as in the case of associating compounds, like methanol, for the development of the NRTL-PRA model [14] from the original NRTL-PR equation [15]. Indeed, in addition to the fact that 
critical parameters of ions are unknown, it is commonly assumed that salts are not present in the vapor phase, so that great attention must be paid to the calculation of phase equilibria.

For this purpose, it is worth recalling the general conditions of the modeling of mixtures containing salts:

- Preliminary to the introduction of salts, all phases considered (liquid or vapor), are described by means of the same number of compounds, $p_{S F}$, usually called "solvent" or "salt-free" components, with the corresponding mole numbers, $n_{S F_{i}}$, and fractions, $x_{S F_{i}}$ :

$$
x_{S F_{i}}=n_{S F_{i}} / n_{S F}, n_{S F}=\sum_{i=1}^{p_{S F}} n_{S F_{i}}
$$

Phase equilibrium conditions at given temperature and pressure satisfy the system of $p_{S F}$ equations (3) described in paragraph 2.1.

- The introduction of salts in the previous mixture always follows the same procedure (Appendix B): a well known amount, $m_{0}$, of salt is introduced in a well known amount of $n_{S F_{i}}$ moles of the initial solvent (such as, for instance, the mole number $m_{0}$ of a given salt per kilogram of water, of solvents, ..). The dissociation of salts into $p_{i o n}$ ions leads, obviously, to the increased total component number, $p_{t o t}=p_{S F}+p_{i o n}$, and mole numbers, $n_{i}$, and fractions, $x_{i}$, of the liquid phase:

$x_{i}=n_{i} / n_{\text {tot }}, n_{\text {tot }}=n_{S F}+n_{\text {ion }} \quad$ and: $\quad n_{\text {ion }}=\sum_{k=1}^{p_{\text {ion }}} n_{\text {ion }}$

However, thanks to this procedure, the additional $p_{i o n}$ variables $n_{i o n_{k}}$ are only functions of the $p_{S F}$ mole numbers, $n_{S F_{i}}$ of the "salt-free" components. Hence, the real number of independent variables is still equal to $p_{S F}$. Consequently, equilibrium conditions at given temperature and pressure must still satisfy the system of $p_{S F}$ equations (3). The introduction of salts in the liquid phase "only" modifies the expressions of the excess Gibbs energy $g_{E O S}^{E}$ model and the derived fugacity coefficients.

\section{1- Phase equilibria calculation with mixtures containing salts}

First of all, the assumption that salts are not present in the vapor phase means that equilibrium conditions at given temperature $T$ and pressure $P$, must be restricted to the $n_{S F_{i}}$ mole fractions of the salt-free components $i$ present in all phases. In the case of vapor-liquid equilibria (VLE), this leads to solve the following equilibrium conditions:

$$
\varphi_{i}^{(L)} x_{S F_{i}}^{(L)}=\varphi_{i}^{(V)} x_{S F_{i}}^{(V)} \quad\left(i=1, p_{S F}\right)
$$

where $\varphi_{i}$ is the fugacity coefficient of component $i$ derived, for the NRTL-PRA EoS, from the compressibility factor of the Peng-Robinson EoS [16]:

$$
Z=\frac{1}{1-\eta}-Q(\eta) \alpha, \quad Q(\eta)=\frac{1}{1+2 \eta-\eta^{2}} \quad \text { with: } \quad \eta=\frac{b}{v}
$$


in which, the attractive term $\alpha$ is estimated in the $\mathrm{EoS} / \mathrm{g}^{\mathrm{E}}$ formalism using the generalized reference state [17]:

$$
\alpha=\frac{a}{b R T}=\sum_{i=1}^{p_{S F}} x_{S F_{i}} \frac{a_{i}}{b_{i} R T}-\frac{1}{0.53}\left[\frac{g_{E o S}^{E}}{R T}\right] \quad, \quad b=\sum_{i=1}^{p_{S F}} x_{S F_{i}} b_{i}
$$

where, $a_{i}$ and $b_{i}$ are estimated from the critical temperature and pressure, $T_{c i}$ and $P_{c i}$ (Appendix A). Hence, salts, the critical parameters of which are unknown, are excluded from the estimation of this part of the compressibility factor $Z$.

On the other hand, the $g_{E o S}^{E}$ excess Gibbs energy in Eq. (3) only accounts for components really present in each phase:

$$
\begin{array}{lll}
\text { vapor phase : } & g_{E o S}^{E}\left(T, n_{S F}\right) \quad, \quad\left(n^{V}=n_{t o t}=n_{S F}\right) \\
\text { liquid phase: } & g_{E o S}^{E}\left(T, n_{S F}, n_{i o n}\right) \quad, \quad\left(n^{L}=n_{t o t}=n_{S F}+n_{i o n}\right)
\end{array}
$$

The general expression of $g_{E o S}^{E}$ proposed in this work for mixtures containing salts is described in the next section. However, it can already be evidenced with the above relations, especially for the aqueous liquid phase that contains both solvents and ions, that the estimation of fugacity coefficients from Eq. (3) (it means from only salt-free components) should be undertaken very carefully. Indeed, their right thermodynamic expression derived from the Peng-Robinson EoS (Eq. (4)) is described by the following relation:

$$
\ln \varphi_{i}=\frac{b_{i}}{b}(Z-1)-\ln Z(1-\eta)-Q(\eta)\left(\frac{\partial n_{S F} \alpha}{\partial n_{S F_{i}}}\right)_{n_{S F_{j}}, T} / R T
$$

in which the derivatives of the $\alpha$ term (Eq. (5)) must be expressed as $\left[\partial\left(n_{S F} g_{E o S}^{E} / R T\right) / \partial n_{S F_{i}}\right]_{n_{S F_{j}}, T}$ Appendix B presents, for the aqueous liquid phase, the main steps of the calculation of this derivative starting from the classical derivatives $\left[\partial\left(n_{t o t} g_{E o S}^{E} / R T\right) / \partial n_{i}\right]_{n_{j}, T}$ of $g_{E o S}^{E}\left(T, n_{S F}, n_{i o n}\right)$ (Eq. (7)).

\section{2- Excess Gibbs energy $g_{E O S}^{E}$ for electrolyte mixtures}

The NRTL-PRA excess Gibbs energy proposed for the simultaneous prediction of LLE, VLE and $\mathrm{h}^{\mathrm{E}}$ of hydrocarbon mixtures with associating compounds [14] is extended to mixtures containing salts by modifying the residual excess Gibbs energy as follows:

$$
g_{\text {EoS }}^{E}=g_{\text {res }}^{E}+g_{\text {diss }}^{E} \quad, \quad g_{\text {res }}^{E}=g_{S M R}^{E}+g_{L R}^{E}
$$

where $g_{\text {res }}^{E}$ and $g_{\text {diss }}^{E}$ represent respectively the residual term, taking account for all component interactions, and the dissociation term relative to the decrease of interactions between associating components during mixings. As outlined in the introduction, the residual term is expressed with respect to two contributions only: the $g_{S M R}^{E}$ term, specific of "Short and Middle Range" interactions 
between solvents and salts, and the $g_{L R}^{E}$ contribution for the description of "Long Range" electrostatic interactions.

The key point of the Short-Middle-Range excess Gibbs energy proposed in this work:

$$
g_{S M R}^{E}=\sum_{i=1}^{p_{\text {tot }}} x_{i} q_{i} \sum_{j=1}^{p_{\text {tot }}} \frac{x_{j} q_{j} G_{j i}}{\sum_{m} x_{m} q_{m} G_{m i}} \Gamma_{j i} \quad, \quad G_{j i}=\exp \left(\Gamma_{j i} / R T\right)
$$

is the representation of all interactions involving "solvents" by means of only one single term. Indeed, the residual term $g_{\text {res }}^{E}$ of the original model [14,15] was already consistent with the virial expressions considered in literature [8-10,12] for the description of the "Middle-Range" interactions between solvents and ions.

The expressions of surface area factors $q_{i}$ of pure components $i$ and binary interaction parameters $\Gamma_{j i}$ between components $i$ and $j$ with respect to the model group contribution parameters $Q_{k}$ and $\Gamma_{L K}$ are recalled in Appendix C. The introduction of salts requires the following modifications:

- Surface area factors $q_{i}$. They are estimated thanks to Eq. (C2), using for solvents the group parameters of UNIFAC [21, 22]. Regarding ions: we have first selected, for $\mathrm{Cl}^{-}$, the values of parameters $Q_{k}$ and $R_{k}$ proposed by Larsen et al. [23] and deduced "realistic" estimations for $\mathrm{Na}^{+}$ (about half of $\mathrm{Cl}^{-}$parameter values). Then, accounting for the evolution of the "ionic radius" ${ } r_{k}$ (published by Shannon [24] and reported in Table 1), the group interaction parameters of anions and cations were estimated as follows, for instance for the surface area factors: $Q_{\text {anion }}=Q_{\mathrm{Cl}^{-}}\left(\mathrm{Ir}_{\text {anion }} / \mathrm{Ir}_{\mathrm{Cl}^{-}}\right), Q_{\text {cation }}=Q_{\mathrm{Na}^{+}}\left(\mathrm{Ir}_{\text {cation }} / \mathrm{Ir}_{\mathrm{Na}^{+}}\right)$.

The values of all subgroup parameters $Q_{k}$ and $R_{k}$ are reported in Table 1.

- Binary interaction parameters $\Gamma_{j i}$. The estimation of the new interaction parameters $\Gamma_{\text {solvent/ion }}$ was performed, assuming for a given salt $\left(C_{k+} A_{k-}\right)$, the rather usual assumptions: (1) no interactions between water and ions: $\Gamma_{\mathrm{H}_{2} \mathrm{O} / \mathrm{C}^{+}}=\Gamma_{\mathrm{H}_{2} \mathrm{O} / \mathrm{A}^{-}}=0$, (2) no interactions between ions: $\Gamma_{C^{+} / A^{-}}=0$.

The dependence of interaction parameters with respect to temperature is described in Appendix C; corresponding values of parameters $\Gamma_{L K}^{(0)}, \Gamma_{L K}^{(1)}$ and $\Gamma_{L K}^{(2)}$ are reported, respectively, in Tables $2 \mathrm{a}, 2 \mathrm{~b}$ and $2 \mathrm{c}$.

For the "Long Range" electrostatic interactions, $g_{L R}^{E}$, we have considered the modeling proposed by Sieder and Maurer [12] based on the original work of Pitzer-Debye-Hückel [4]:

$$
g_{L R}^{E}=-R T\left[\frac{4 A_{x} I_{z}}{\chi} \ln \left(1+\chi \sqrt{I_{z}}\right)\right]
$$

where, $I_{z}$, is the ionic strength : 


$$
I_{z}=I_{z}\left(x_{i o n}\right)=\frac{1}{2} \sum_{k=1}^{p_{i o n}} x_{\text {ion }_{k}} Z_{k}^{2}
$$

with, $Z_{k}$ the charge number of ion $k$ and $\chi$ an empirical parameter depending on the solvent properties and expressed with respect to the salt-free mole fractions:

$$
\chi=\chi\left(x_{S F}\right)=2 / \sqrt{M^{*}}, \quad M^{*}=\sum_{i=1}^{p_{S F}} x_{S F_{i}} M_{i}
$$

The electrostatic properties of the solvent mixture are characterized by means of parameter $A_{x}$ :

$$
A_{x}=A_{x}\left(T, x_{S F}\right)=\frac{1}{3}\left(\frac{2 \pi N_{a}}{v^{*}}\right)^{1 / 2}\left(\frac{e^{2}}{4 \pi \varepsilon_{0} \varepsilon_{r}^{*} k T}\right)^{3 / 2}
$$

with, $N_{a}$ the Avogadro's number, $v *$ the molar volume of the salt-free solvent, $e$ the charge of one electron, $\varepsilon_{0}$ the vacuum permittivity of vacuum, $\varepsilon_{r}^{*}$ the relative permittivity of the salt-free solvent mixture and $k$ the Boltzmann's constant.

The molar volume $v^{*}$ and the relative permittivity $\varepsilon_{r}^{*}$ of the salt-free solvent mixture are expressed according to [12], as:

$$
v^{*}=\sum_{i=1}^{p_{S F}} x_{S F_{i}} b_{i} \quad, \quad \varepsilon_{r}^{*}=\sum_{i=1}^{p_{S F}} x_{S F_{i}} b_{i} \varepsilon_{r_{i}} / v *
$$

The method considered in this work for the estimation of the relative permittivity $\varepsilon_{r i}$ of compound $i$ is discussed in paragraph 3; estimated values of $\varepsilon_{r}(T)$ required for the modeling of mixtures studied in this work are reported in Table 3.

The excess Gibbs energy $g_{\text {diss }}^{E}$ was specially introduced in the NRTL-PRA model [14] in order to allow the simultaneous representation of LLE, VLE, and $\mathrm{h}^{\mathrm{E}}$ for mixtures containing associating compounds (such as methanol) in presence of heavier non associating compounds (long chain paraffins, cycloalkanes, ...). During such mixings, the decrease of interactions between the associating components $i$ (asso) leads to a significant variation of the global mole fraction of polymers: from $X_{i(\text { asso })}^{\left(x_{i}=1\right)}$, for the pure associating component, towards $X_{i(\text { asso })}$, for the global mole fraction $x_{i}=x_{i(a s s o)}$. The NRTL-PRA model proposed the following expression of this dissociation excess Gibbs energy :

$$
g_{\text {diss }}^{E}=\sum_{i=i(\text { asso })}\left(x_{i} X_{i}^{\left(x_{i}=1\right)}-X_{i}\right) E_{i(\text { asso })}^{0}, \quad E_{i(\text { asso })}^{0}=\Delta G_{i}^{0}-(2 / z) E_{i i} \quad(z=10)
$$

where, the association energy, $E_{i(\text { asso })}^{0}$, only depends on the experimental value of the hydrogen bond free enthalpy, $\Delta G_{i}^{0}$ and the estimation of the energy, $E_{i i}$, thanks to the model group contribution parameters (Appendix C).

The global mole fraction $X_{i}$ of polymers is expressed from the knowledge of the "pseudo equilibrium constant" $K_{i}=\exp \left(-\Delta G_{i}^{0} / R T\right) / \mathrm{gam}_{i}$ using the following equilibrium relations: 


$$
X_{i}=X_{i 1} /\left(1-K_{i} X_{i 1}\right), X_{i 1}=\left[\left(1+2 K_{i} x_{i}\right)-\sqrt{1+4 K_{i} x_{i}}\right] /\left[2 K_{i}^{2} x_{i}\right]
$$

and the estimation of the mixture parameter:

$$
\operatorname{gam}_{i}=x_{i}+\sum_{m \neq i(\text { asso })} x_{m}\left(\sigma_{m, i} / \sigma_{i}\right)
$$

which accounts for the polarity: $P_{m}=\sum_{k} v_{m k} P_{k}$ and structural parameters $r_{m, i}$ characterizing the mixture components: $\sigma_{m, i}=r_{m, i}\left(P_{i}-P_{m}\right), \quad r_{m, i}=\sum_{k} v_{m k} R_{k} S_{k}$; the values of corresponding parameters $R_{k}, S_{k}$ and $P_{k}$ are reported in Table 1.

It should be recalled that mixtures containing only associating compounds (as methanol, water or other alcohols) are assumed to be miscible mixtures, it means without phase splitting. In this case, it was shown [14] that parameter values of $P_{m}$ fixed to 1 in Table 1 , for these compounds, lead to $g_{d i s s}^{E}=0$; in this work, the same condition, $P_{m}=1$, was extended to ions.

Until now, the dissociating term of the NRTL-PRA model was only taken into consideration for mixtures containing methanol, since only them required the simultaneous representation of LLE, VLE, and $h^{\mathrm{E}}$ [14]. Consequently, for all solvent mixtures studied in this work (except for methanol with carbon dioxide in presence of water) the estimation of the $g_{\text {diss }}^{E}$ term (Eq. (16)) was not required; for this reason, no value of hydrogen bond free enthalpy, $\Delta G_{i}^{0}$, was reported in parameter tables.

\section{Results and discussion}

\section{1- Preliminary modeling: mixtures with water and permittivity of pure compounds}

The modeling of light gases and alcohols with water and salts required the following preliminary studies.

- Mixtures of light gases with water. The VLE of mixtures of light gas and water was revisited in view of a better representation of high pressure data, taking into account [14] the dependence of group contribution parameters with respect to temperature (Eq.(C-3)). Fig. 1 shows the rather good predictions obtained for methane, carbon dioxide, nitrogen and hydrogen sulfide with water.

- Alcohol-water and alcohol-paraffin mixtures. The NRTL-PRA model was also extended [25] to the modeling of VLE and excess enthalpies $\mathrm{h}^{\mathrm{E}}$ of alcohol-water and alcohol-paraffin mixtures from ethanol to pentanol. It is worth recalling that, like for methanol [14], higher alcohols were modeled by means of one hydroxyl group "OH" and paraffinic main groups "PAR" (Table 1). As expected, methanol, ethanol, as well as primary and secondary alcohols, were described with specific groups in Tables 2.

- Correlation of the relative permittivity $\varepsilon_{r}(T)$. A first study of mixtures containing respectively water and methanol with sodium chloride was performed using classical correlations proposed in literature [26-28]; as illustrated in Figs. 2a and 2b, respectively for these two solvents, a "strange" behavior of $\varepsilon_{r}(T)$ was observed, especially for water, at temperatures greater than $350 \mathrm{~K}$. 
Taking into consideration "data" generated from various literature correlations (Chunxi and Fürst [26] for water, Dannhauser and Bahre [27] for methanol and CRC tables [28] for other solvents of interest) a generalized function has been proposed for polar compounds [29]:

$$
\varepsilon_{r}=A+B T+C T^{2}+D / T+E \ln (T)
$$

with two objectives: first, to obtain the best representation of the "experimental domain" defined by the CRC tables (as illustrated, for instance, in Fig. 2a for water and in Fig. 2b for methanol); second, to allow a reasonable extrapolation of the reduced permittivity $\varepsilon_{r}$ at high temperatures, it means up to $600 \mathrm{~K}$ (as required for the modeling of methane or carbon dioxide mixtures with water and salts in Figs. 1 and 4); values of parameters $A, B, C, D$ and $E$ for all polar compounds considered in this work are reported in Table 3.

Concerning light gases, for which values of $\varepsilon_{r}$ are known to be "small" and "rather constant" with respect to temperature, we have adopted, as described in Table 3, the values proposed by the CRC tables at a given reference temperature.

\section{2- Modeling of mixtures containing sodium chloride}

Sodium chloride being the main seawater salt (at around $85 \%$ of all salts), a large amount of experimental VLE data was available in literature, especially with methane, carbon dioxide, hydrogen sulfide and methanol. Data referenced in Table 4 only concern the experimental data at pressures up to 600 bar considered for the estimation of the group contribution parameters $\Gamma_{L K}^{(0)}, \Gamma_{L K}^{(1)}$ and $\Gamma_{L K}^{(2)}$ (Eq. (C-3)) required for the calculation of the binary interaction parameters $\Gamma_{\mathrm{Na}^{+} / \text {solvent }}$ and $\Gamma_{\mathrm{Cl}^{-} / \text {solvent }}$ in the $g_{S M R}^{E}$ Gibbs energy (Eq.(10)).

The objective function $F_{o b j}$ minimized was:

$$
F_{o b j}=\sum_{i=1}^{N_{P}}\left(\Delta P / P^{\exp }\right)_{i}^{2}+\sum_{i=1}^{N_{T}}\left(\Delta T / T^{\exp }\right)_{i}^{2}+\sum_{i=1}^{N_{y}}\left(\Delta y_{1} / y_{1}^{\exp }\right)_{i}^{2}
$$

where $\Delta P, \Delta T$ and $\Delta y_{1}$ are, respectively, the deviations between experimental and calculated values on bubble points and vapor mole fractions; $N_{P}, N_{T}$ and $N y$ are the corresponding number of data points. This led to the following mean deviations reported in Table 4:

$$
\Delta P / P \%=\frac{100}{N_{P}} \sum_{i=1}^{N_{P}}\left|\Delta P / P^{e x p}\right|_{i}, \Delta T / T \%=\frac{100}{N_{T}} \sum_{i=1}^{N_{T}}\left|\Delta T / T^{\exp }\right|_{i}, \quad \Delta y / y \%=\frac{100}{N_{y}} \sum_{i=1}^{N_{y}}\left|\Delta y_{1} / y_{1}{ }^{\text {exp }}\right|_{i}
$$

Results of the correlation reported in this table evidence that standard deviations must be considered very carefully for VLE data at high pressures, especially for mixtures containing light gases. For mixtures with alcohols at low pressures, deviations are more reliable and the model provides rather good estimations of VLE data. At the end, these global results led us to consider that the proposed data set was significant enough to provide reliable estimations, especially for the $\Gamma_{\mathrm{Cl}^{-} / \text {solvent }}$ values; hence the estimated group contribution parameters, $\Gamma_{L K}$, reported in Tables $2 \mathrm{a}$, $2 \mathrm{~b}$ and $2 \mathrm{c}$, will remain unchanged for the modeling of other salts in section 3.4. 
Finally, global results were illustrated with figures 3 to 6 , where phase diagrams are represented with respect to the salt-free mole fraction $x_{1}$ of the solvent component (1). The analysis of the various predictions calls the following remarks.

- Methane: Figs. 3a and 3b illustrate the modeling proposed with the NRTL-PRA model at 408 K; the prediction of VLE data up to very high pressures, about 1400 bar, appears to be rather reliable. The representation proposed by Courtial et al. [3] with the eCPA equation at the same temperature is presented in Fig. 3c; both models lead to quite similar results.

- Carbon dioxide: Fig. 4a presents the NRTL-PRA predictions of VLE from $323 \mathrm{~K}$ to $450 \mathrm{~K}$, for a molality $m_{0}=1.0 \mathrm{~mol} . \mathrm{kg}^{-1}$; very good results were thus obtained in these conditions, up to 500 bar. It should be pointed out that similar results are also previously obtained, for the same range of temperatures and pressures, with other literature models, such as: for cubic EoS, the PSRK-LIFAC [9], VTPR-LIFAC [10] and the extension of the PR EoS to electrolytes proposed by Sieder and Maurer [12]; and, for SAFT equations, the SAFT1-RPM (Ji. et al. [30]) and SAFT-LJ (Sun and Dubessy [31]) models.

Results obtained at $572 \mathrm{~K}$ are illustrated in Fig. 4b; for the same amount of salt, the NRTL-PRA equation predicts a closed phase envelope, in agreement with results obtained without salt; however, in this case, this behavior does not agree with the experimental data of Takenouchi and Kennedy [32] which suggest, in the same conditions, an open phase envelope with pressures up to 1500 bar. For this purpose, a comparison with the eCPA model [3] was also performed in Fig. 4c; it can be observed that this modeling follows the tendency suggested by Takenouchi and Kennedy, but, however, with a less favorable behavior of the vapor phase beyond 500 bar.

- Nitrogen and hydrogen sulfide: results presented in Fig. 5 deal with more moderate pressures; even if less meaningful, the proposed correlations are still reasonable. Results obtained with hydrogen sulfide in Fig. 5a are still in agreement with those proposed by Li et al. [9] with the PSRK-LIQUAC model in the same domain.

- Methanol and ethanol: as usual for mixtures containing alcohols, results presented in Fig. 6 correspond to a fixed mole fraction, $x_{\text {salt }}$, of sodium chloride. Calculations of VLE under 1.0 bar are quite satisfactory. It should be also noted that curves presented in Fig. 6a for methanol, under atmospheric pressure, are in complete agreement with those proposed, in the same conditions, by Sieder and Maurer [12] by means also of a cubic PR EoS "extended" to electrolytes.

\section{3- Prediction of system carbon dioxide-methanol-water-sodium chloride.}

\section{- Prediction of VLE data}

In order to check the limits of the proposed method, we have considered the quaternary system: carbon dioxide - methanol - water - sodium chloride, with the experimental data of Pèrez Salado Kamps et al. [33], not included in our data base. The authors have performed various sets of measurements corresponding to different values of the solvent composition and amount of salt introduced in the mixture; the following characteristic parameters were considered:

$$
\rho=n^{(2)} /\left(n^{(2)}+n^{(3)}\right) \text { and } m_{s}=n_{\mathrm{NaCl}} / k g(\text { methanol }+ \text { water })
$$


$\rho$, represents the "so called" « solute-free solvent mixture composition » and $m_{s}$ is the molality of sodium chloride with respect to (methanol+water) mixtures.

Predictions presented in Fig. 7 are also quite good and agree with the curves proposed by Sieder and Maurer [12] for the same system, in the same experimental conditions. Results seem therefore very encouraging for further extensions of the NRTL-PRA model.

\section{- Detailed example of the VLE method.}

This quaternary system was also considered in Appendix D for illustrating the calculation method described in section 2. It should be mentioned that, contrary to all other mixtures considered in this work, the system methanol with carbon dioxide in presence of water is the only one which requires the estimation of the $g_{\text {diss }}^{E}$ term (paragraph 2.2).

\section{4- Mixtures with other salts}

Besides sodium chloride, other salts containing mainly magnesium, calcium and potassium associated with chlorine were also considered as representative of seawater properties. As can be seen in Table 5, which details the VLE data available in literature: the information concerning mixtures of methane with all salts, is rather reasonable; however, for carbon dioxide, ethanol and 1propanol, experimental data are limited to only two or three salts.

As suggested previously, the modeling of these data only consists in the estimation of the

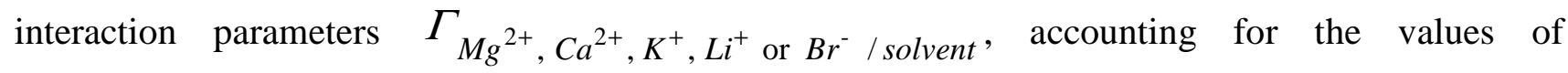
$\Gamma_{\mathrm{Cl}^{-} / \text {solvent }}$ parameters previously determined in section 3.2. Data were regressed in the same way as for mixtures with sodium chloride (Eq. (20)); deviations thus obtained (Eq. (21)) are given in Table 5 and the corresponding group contribution parameters are reported in Tables 2a, 2b, 2c.

Even if the results presented in Table 5 concern a more restricted range of pressures, similar conclusions to those of Table 4 can be drawn: deviations corresponding to mixtures with methane and carbon dioxide should still be considered carefully; for mixtures with alcohols, results are more significant and satisfactory.

The major results obtained with the various salts are also illustrated with some meaningful figures (Figs. 7-10) and the following remarks.

- Methane: data of methane-water with $\mathrm{MgCl}_{2}$ and $\mathrm{LiCl}$, respectively at $298 \mathrm{~K}$ (Fig. 8a) and $313 \mathrm{~K}$ (Fig. 8b), focus rather on moderate pressures (up to 100 bar), compared to those presented in Fig. 3 with sodium chloride. Hence, results are rather good and deviations are similar to those obtained in literature with other salts: $\mathrm{CaCl}_{2}$, in the case of the PSRK-LIFAC [9] model, or $\mathrm{LiBr}$ and $\mathrm{KBr}$, my means of the VTPR-LIFAC [10] equation.

- Carbon dioxide: pressures considered in Fig. 9a, for mixtures containing $\mathrm{KCl}$ at $313 \mathrm{~K}$, are much higher (up to 400 bar); the estimation of VLE with $\mathrm{CaCl}_{2}$ (Fig. 9b) at $298 \mathrm{~K}$ is still limited at 60 bar. In both cases, the model leads to rather good representations. In this case, we also observed, with $\mathrm{CaCl}_{2}$, that both NRTL-PRA and PSRK-LIFAC [9] models lead to the similar modeling.

- Ethanol and 1-propanol: data presented in Table 5, respectively for ethanol with $\mathrm{LiBr}$ and 1propanol with $\mathrm{KBr}$, correspond to experimental measurements performed, at each pressure 
(Fig. 10a) or temperature (Fig. 10b), for variable values of the molality $m_{0}$. Hence, both figures only present the calculated properties with respect to the experimental values. Results remain, however, quite meaningful (less than 2\%, even for 1-propanol with $\mathrm{KBr}$ ). We can also note that other literature results presented with VTPR-LIFAC [10] for ethanol and 1-propanol, with LiCl and $\mathrm{LiBr}$, but under atmospheric pressure, were also rather satisfactory.

\section{Conclusion}

The purpose of the present work was to extend the fundamental bases of the NRTL-PRA EoS [14] to the prediction of phase equilibria in mixtures containing electrolytes. However, it should be recalled that the presence of electrolytes in a mixture does not only require a new modeling of the $g_{E o S}^{E}$ excess Gibbs energy; indeed, not only critical parameters of ions are unknown, but it is commonly assumed that salts are not present in vapor or hydrocarbon liquid phases, so that great attention must be paid to the calculation of phase equilibria.

In the proposed modeling, the $a$ and $b$ parameters of the cubic EoS only depend on the solvent mole fractions (salt-free), while the $g_{E o S}^{E}$ excess Gibbs energy is still described with: the residual term, $g_{\text {res }}^{E}$, taking account for all component interactions, and the dissociation term, $g_{\text {diss }}^{E}$, relative to the decrease of interactions between associating components during mixings; nevertheless, as pointed out in paragraph 2.2, for all solvent mixtures considered in this work (except for methanol with carbon dioxide in presence of water) the estimation of the $g_{\text {diss }}^{E}$ term was not required. The presence of electrolytes leads to a major modification of $g_{\text {res }}^{E}$; contrary to other cubic EoS, the proposed version describes all the interactions between solvents and ions with only two contributions: the SMR term, specific of "Short and Middle Range" interactions between solvents and salts, and the $L R$ relation of Pitzer-Debye-Hückel [4], for the "Long Range" electrostatic interactions.

The main interest of the proposed method is not only the reduction of the interaction parameters in the $S M R$ term; in fact, the key point of the modeling is that $g_{S M R}^{E}$ is simply expressed with the original $g_{\text {res }}^{E}$ of the NRTL-PRA model $[14,15]$, since it was already consistent with the virial expressions considered in literature [8-10,12] for the description of the "Middle-Range" interactions between solvent and ions. Thanks to these theoretical bases, it was expected that the modeling of mixtures containing salts would lead, with a lower number of estimated parameters, to more reliable predictions.

The purpose of this work was, therefore, to verify these assumptions. The following mixtures were considered: light gases at high pressures (methane, carbon dioxide, nitrogen and hydrogen sulfide) and alcohols (methanol, ethanol and 1-propanol) with water and salts. The VLE in presence of sodium chloride and other strong electrolytes (mainly, magnesium, calcium and potassium associated with chlorine) were modeled with the proposed electrolyte version of the NRTL-PRA model. The rather satisfactory modeling obtained using a large data base from open literature can be considered as significant tests for the capacity of the NRTL-PRA equation to represent mixtures containing light gases and alcohols with water and salts. The analysis of results obtained with other literature models has also shown that: 
- concerning other cubic EoS: quite similar results were obtained, at moderate temperatures, for all mixtures investigated. The main interest of the proposed version is, probably that: first, the modeling requires "less regressed" model parameters; second, that it allows rather "safe predictions " at high temperatures and pressures, as for methane and carbon dioxide with water and sodium chloride.

- regarding non cubic EoS, as SAFT and CPA versions, rather few papers could be found for the representation of systems considered in the present study, except for carbon dioxide with water and sodium chloride: SAFT [30, 31], in the subcritical domain of salt-free systems, and eCPA [3], at high pressures and temperatures; other papers concerning aqueous mixtures with carbon dioxide (with Brine and sodium chloride [34]) or hydrogen sulfide (PVT properties of imidazolium based ionic liquids [35]) were, obviously, not considered herewith. Nevertheless, with respect to cubic EoS, the great advantage of SAFT versions (SAFT-VRE [2] or ePCA-SAFT [1,36]) is the capacity of predicting a wide field of physical properties (vapor pressure and liquid densities of aqueous solutions with salts, activity coefficients, osmotic pressure ...).

In the present state, results obtained in this work seem very encouraging for further extensions of the NRTL-PRA model. Until now, we have only focused on the representation of VLE with a single electrolyte; the next work will be dedicated: first, to the modeling of LLE and SLE, and then, to the representation of mixtures containing several salts.

The extension of the proposed model to weak electrolytes, would require, for instance with acetic acid, the introduction of an ionization constant [37], but also of chemical equilibrium of dimerization $[12,38]$, as with associating compounds. Therefore, this development could only be considered in future works.

\section{Acknowledgements}

The authors would like to gratefully thank Olivier Baudouin (ProSim) and Isabelle Raspo (M2P2) for valuable discussions.

\section{List of symbols}

$\begin{array}{ll}a & \text { attractive term } \\ b & \text { covolume } \\ \text { Fobj } & \text { objective function } \\ G & \text { molar Gibbs free energy } \\ K & \text { Boltzmann's constant. } \\ \text { Ir } & \text { ionic radius } \\ m_{0} & \text { molality (with respect to water) } \\ m_{s} & \text { molality (with respect to water }+ \text { methanol) } \\ n & \text { mole number } \\ N & \text { number of data points } \\ N_{a} & \text { Avogadro's number } \\ P & \text { pressure } \\ p & \text { component number } \\ q & \text { surface area factor }\end{array}$




$\begin{array}{ll}R & \text { ideal gas constant } \\ Q_{k}, R_{k}, S_{k}, P_{k} & \text { NRTL-PRA subgroup contribution parameters } \\ T & \text { temperature } \\ v & \text { molar volume } \\ Z & \text { compressibility factor } \\ x & \text { mole fraction } \\ X & \text { mole fraction of polymers } \\ y & \text { vapor phase composition }\end{array}$

Greek letters

$\begin{array}{ll}\alpha & \text { alpha function } \\ \mathcal{E} & \text { permittivity } \\ \Phi & \text { fugacity coefficient } \\ \Gamma_{j i} & \text { interaction parameter between molecules } j \text { and } i \\ \Gamma_{L K} & \text { interaction parameter between main groups } K \text { and } L \\ \omega & \text { acentric factor } \\ \rho & \text { solute-free solvent factor } \\ \theta_{i K} & \text { probability that a contact from molecule } i \text { involves a main group } K \\ v_{i K} & \text { number of main group } K \text { in molecule } i\end{array}$

\section{Subscript}

diss dissociation property

$i \quad$ pure component property

ion number of ions

$L R \quad$ Long Range interaction

obj objective function

$P, T, y \quad$ pressure, temperature, vapor mole fraction

res residual property

salt number of salts

SF $\quad$ salt-free

SMR Short-Middle Range interaction

tot total number of components : SF (solvents) + ions

Superscript

E excess property at constant pressure

\section{APPENDIX A. EoS pure component parameter estimation}

The attractive term $a_{i}$ and the covolume $b_{i}$ in Eq. (5) are estimated from the critical temperature and pressure, $T_{c i}$ and $P_{c i}$ respectively, by the formulae:

$$
a_{i}=0.45723553 \frac{R^{2} T_{c_{i}}^{2}}{P_{c_{i}}} f\left(T_{r}\right), b_{i}=0.07779607 \frac{R T_{c_{i}}}{P_{c_{i}}}
$$


where $T_{r}$ is the reduced temperature, $T_{r}=T / T_{c_{i}}$, and $f\left(T_{r}\right)$ is the generalized Soave function [18]:

$$
f\left(T_{r}\right)=\left[1+m\left(1-T_{r}^{\gamma}\right)\right]^{2}
$$

For hydrocarbons and non associating compounds, we still consider the original Soave function [19] corresponding to $\gamma=0.5$ with the parameter $m$ correlated to the acentric factor $\omega$ through the generalized expression proposed by Robinson and Peng [20]:

$$
\begin{aligned}
& m=0.37464+1.54226 \omega-0.26992 \omega^{2} \quad \text { if } \omega \leq 0.49 \\
& m=0.379642+1.48503 \omega-0.164423 \omega^{2}+0.016666 \omega^{3} \quad \text { if } \quad \omega>0.49
\end{aligned}
$$

On the other hand, for associating compounds, $\gamma$ and $m$ parameters are estimated with the values previously proposed in [18] to improve vapor pressure representations $(\gamma=0.65, m=0.6864$ for water and $\gamma=0.9, m=0.6969$ for methanol).

\section{APPENDIX B. Calculation of partial derivatives in variables $\left(\boldsymbol{T}, \boldsymbol{n}_{S F}\right)$ from $g_{E o S}^{E}\left(T, n_{S F}, n_{i o n}\right)$}

The modeling of phase equilibria in mixtures containing strong electrolytes assumes that a given amount, $n_{\text {salt }}$, of a salt $\left(C_{k+} A_{k-}\right)$, leading to $n_{\text {ions }_{k}}$ of each type $k+$ and $k-$, is introduced in $n_{S F}$ moles of the salt-free solvent. The partial derivatives are estimated as described below.

(1)- Properties of the "solvent+salt" mixture. If $n_{\text {salt }}$ is the mole number of salt introduced per mole of component $i$ of the solvent (mainly water, in classical applications), the total mole numbers of salt and ions are:

$$
n_{\text {salt }}=\sum_{i=1}^{p_{S F}} n_{\text {salt }} n_{S F_{i}}, \quad n_{\text {ion }}=\sum_{k=1}^{p_{\text {ion }}} n_{\text {ion }} \quad \text { with : } \quad n_{\text {ion }}=k n_{\text {salt }}=k \sum_{i=1}^{p_{S F}} n_{\text {salt }} n_{S F_{i}}
$$

Thus, the excess Gibbs energy $g_{E o S}^{E}\left(T, n_{S F}, n_{i o n}\right)$ proposed in Eq. (7) by the NRTL-PRA model depends on $p_{t o t}=p_{S F}+p_{\text {ion }}$ variables representing the mole numbers of "solvent" $\left(n_{S F}\right)$ and "ions" $\left(n_{i o n}\right)$. Nevertheless, as shown in the last term of (B-1), the $p_{i o n}$ variables $n_{i o n_{k}}$ are only functions of the $p_{S F}$ variables $n_{S F_{i}}$; hence, the real number of independent variables is the $p_{S F}$ mole numbers $n_{S F_{i}}$ of the "salt-free" components.

However, the classical estimation of the partial derivatives, $\left[\partial\left(n_{t o t} g_{E o S}^{E}\right) / \partial n_{i}\right]_{n_{j}, T}$, with respect to all the mole numbers really present in the liquid phase, does not represent the required derivatives expressed in Eq.(8). The following calculations should be performed for this purpose.

(2)- Derivatives of $\left(n_{t o t} g_{E o S}^{E}\right)$ with respect to the salt-free mole numbers $n_{S F_{i}}$. For the first derivative we get:

$$
\left[\partial\left(n_{t o t} g_{E o S}^{E}\right) / \partial n_{S F_{i}}\right]_{n_{S F_{j}}, T}=\left[\partial\left(n_{t o t} g_{E o S}^{E}\right) / \partial n_{i}\right]_{n_{j}, T}
$$




$$
+\sum_{k}\left[\partial\left(n_{t o t} g_{E o S}^{E}\right) / \partial n_{i o n_{k}}\right]_{n_{j}, T}\left(\partial n_{i o n_{k}} / \partial n_{S F_{i}}\right)
$$

with, according to Eq. (B-1) : $\left(\partial n_{i o n_{k}} / \partial n_{S F_{i}}\right)=k n_{\text {salt }}$

(the same procedure is applied to the second derivatives)

(3)- Derivatives of $\left(n_{S F} g_{E o S}^{E}\right)$ with respect to the salt-free mole numbers $n_{S F_{i}}$. This function is first expressed as: $n_{S F} g_{E o S}^{E}=\left(n_{S F} / n_{t o t}\right)\left(n_{t o t} g_{E O S}^{E}\right)$ in order to account for the derivatives previously estimated :

$$
\begin{aligned}
{\left[\partial\left(n_{S F} g_{E o S}^{E}\right) / \partial n_{S F_{i}}\right]_{n_{S F_{j}}, T}=\left(n_{S F} / n_{t o t}\right)\left[\partial\left(n_{t o t} g_{E o S}^{E}\right) / \partial n_{S F_{i}}\right]_{n_{S F_{j}}, T} } \\
+g_{E o S}^{E} n_{t o t}\left[\partial\left(n_{S F} / n_{t o t}\right) / \partial n_{S F_{i}}\right]_{n_{S F_{j}}}
\end{aligned}
$$

with : $n_{t o t}\left[\partial\left(n_{S F} / n_{t o t}\right) / \partial n_{S F_{i}}\right]_{S F_{j}}=1-\left(n_{S F} / n_{t o t}\right)\left(\partial n_{t o t} / \partial n_{S F_{i}}\right)_{S F_{j}}$

and, according to Eq. (B-1): $\left(\partial n_{t o t} / \partial n_{S F_{i}}\right)=1+\sum_{i=1}^{p_{S F}} k n_{s a l t_{i}}$

Hence, Eq. (B-4) leads to the rigorous derivatives to use in Eq. (8) for the fugacity coefficients. It is also obvious that, for the vapor phase where the lack of salts leads to: $n_{t o t}=n_{S F}$, the calculation of above formulae (B-2) and (B-4) is unnecessary, since they are strictly equivalent to the partial derivative $\left[\partial\left(n_{t o t} g_{E o S}^{E}\right) / \partial n_{i}\right]_{n_{j}, T}$ required in Eq. (8).

\section{APPENDIX C. Group contribution parameter estimation}

According to the NRTL-PRA model, binary interaction parameters $\Gamma_{j i}$ and $E_{i i}$ in Eqs. (10) and (16) are estimated with the original group contribution method:

$$
\Gamma_{j i}=\sum_{K} \theta_{i K} \sum_{L}\left(\theta_{j L}-\theta_{i L}\right) \Gamma_{L K}, \quad E_{i i}=\sum_{K} \theta_{i K} \sum_{L} \theta_{i L} \Gamma_{L K} \quad, \quad \Gamma_{K K}=0
$$

where $\theta_{i K}$ is the probability that a contact from a molecule $i$ involves a main group $K$ :

$$
\theta_{i K}=\sum_{k} v_{i k(K)} \frac{Q_{k}}{q_{i}} \quad, \quad q_{i}=\sum_{k} v_{i k(K)} Q_{k}
$$

with $v_{i k(K)}$ the number of subgroup $k$ belonging to the main group $K$ in a molecule $i$ and $q_{i}$ its corresponding surface area factor.

The dependence of group contribution parameters $\Gamma_{L K}$ with respect to temperature recently proposed [14] is considered for both solvents and ions:

$$
\Gamma_{L K}=\Gamma_{L K}^{(0)}+\Gamma_{L K}^{(1)}\left(\frac{T_{0}}{T}-1\right)+\Gamma_{L K}^{(2)}\left(\frac{T}{T_{0}}-1\right)
$$


APPENDIX D. Detailed example of the VLE method: system carbon dioxide ${ }^{(1)}$-methanol ${ }^{(2)}$ water $^{(3)}$-sodium chloride.

Table D details, for one "data point", the various steps of the phase equilibrium calculation method proposed in paragraph 2.1. We consider one point $\left(x_{S F}(1)=0.0130\right)$ of the prediction described in Fig. 7a for the experimental data of Pèrez Salado Kamps et al. [31] at 313.66 K, with the characteristic mixture parameters proposed by the authors (Eq. (22)) $: \rho=0.049$ and $m_{s}=1.74$. The exact characteristics of the "selected data point" reported in Table $\mathrm{D}$, are therefore:

$$
T=313.66 \mathrm{~K}, x_{S F}(1)=0.01300, x_{S F}(2)=0.04830 \text { and } x_{S F}(3)=0.93870
$$

with, for one mole of solvent, $n_{S F}=1$, the following mole number of salt, $n_{\text {salt }}=0.03212$, leading thus to:

$$
n_{N a+}=0.03212, n_{C l-}=0.03212 \text { and } n_{t o t}=1.06424
$$

The first part of Table D presents the values of the pure compound parameters required, at temperature $T$, for the modeling: EoS parameters, in Eq.(5), and $g_{E o S}^{E}$ properties, in Eqs. (10, 15). Only the non zero interaction parameters $\Gamma_{j i}$ are reported in this table; the dissociation energy used in Eq. (16) for methanol is, as proposed in [14]: $E_{i(\text { asso })}^{0}=-9980.62-6833.96(298.15 / T-1)$.

The following part of the table details, for the liquid phase, the different steps required, according to Appendix B, for the estimation of the partial derivatives of $g_{E O S}^{E}\left(T, n_{S F}, n_{i o n}\right)$ with respect to mole fractions.

A "bubble point" method is then considered for the estimation of the phase equilibrium conditions described in Eq. (3). At the end of the iterative process, the final values of the pressure and salt-free mole fractions of the vapor phase are:

$$
P=47.672 \text { bar }, \quad y_{S F}(1)=0.99652, y_{S F}(2)=0.00112 \text { and } y_{S F}(3)=0.00235
$$

The last part of Table D provides, both for the liquid and vapor phases, all the details required for the estimation of the fugacity coefficients in Eq. (8).

It can be seen in this table, that the equilibrium conditions (Eq. (3)) characterized by the "equality", for all the compounds $i$, of the products $\varphi_{i} x_{S F_{i}}$ between the liquid and vapor phases, are very well satisfied. This result is obtained thanks to a "reliable and fast" bubble point algorithm based on the use of "analytical derivatives" (previously verified with numerical tests) and "strict" convergence criterions $\left(\Delta\left|\varphi_{i}^{L} x_{S F_{i}}^{L}-\varphi_{i}^{V} x_{S F_{i}}^{V}\right|<10^{-10}\right)$ for the resolution of Eq. (3).

\section{References}

[1] L.F. Cameretti, G. Sadowski, J.M. Mollerup, Ind. Eng. Chem. Res. 44 (2005) 3355-3362.
A. Galindo, A. Gil-Villegas, G. Jackson, A.N. Burgess, J. Phys. Chem. B 103 (1999) 10272- 10281.

X. Courtial, N. Ferrrando, J.C. de Hemptinne, P. Mougin, Geochim. Cosmochim. Acta. 142 (2014) 1-14. 
K.S. Pitzer, J.Phys.Chem. 77 (1973) 268-277.

[5] F.X. Ball, H. Planche, W. Fürst, H. Renon, AICHE J., 31 (1985) 1233-1240.

[6] W. Fürst, H. Renon, AIChE J. 39 (1993) 335-343.

[7] M. Born, Z. Phys. 1(1920) 45-48.

[8] W. Yan, M. Topphoff, C. Rose, J. Gmehling, Fluid Phase Equilib. 162 (1999) 97-113.

[9] J. Li,, M. Topphoff, K. Fisher, J. Gmehling, Ind. Eng. Chem. Res. 40 (2001) 3703-3710.

[10] E. Collinet, J. Gmehling, Fluid Phase Equilib. 246(1-2), (2006), 111-118.

[11] V.Q. Vu, P. Duchet-Suchaux, W. Fürst W., Fluid Phase Equilib. 194-197 (2002) 361-370.

[12] G. Sieder, G. Maurer, Fluid Phase Equilib. 225 (2004) 85-99

[13] R. Masoudi, M. Arjmandi, B. Tohidi, Chem.Eng.Sci., 58 (2003) 1743-1749.

[14] E. Neau, I. Raspo, J. Escandell, Fluid Phase Equilib. 427 (2016) 126-142

[15] J. Escandell, E. Neau, C. Nicolas, Fluid Phase Equilib. 301 (2011) 80-97

[16] D.Y. Peng, D.B. Robinson, Ind. Chem. Fundam. 15 (1976) 59-64.

[17] E. Neau, J. Escandell, I. Raspo, Chem. Eng. Sci. 66 (2011) 4148-4156.

[18] E. Neau, I. Raspo, J. Escandell, C. Nicolas, O. Hernández-Garduza, Fluid Phase Equilib. 276 (2009) 156-164.

[19] G. Soave, Chem. Eng. Sci. 27 (1972) 1197-1340.

[20] D.B. Robinson, D.Y. Peng, Gas Processors Association Research Report, Edmonton-Alberta, 1978.

H.K Hansen, P. Rasmussen, A. Fredenslund, M. Schiller, J. Gmehling, Ind. Eng. Chem. Res., 30 (1991) 2352-2355.

[22] T. Holderbaum, J. Gmehling, Fluid Phase Equilib. 70 (1991) 251-265.

[23] B. L. Larsen, P. Rasmussen, A. Fredenslund, H.K. Hansen, IEC Res, Ind. Eng. Chem. Res, 26 (1987) 2274-2286.

[24] R. D. Shannon, Acta Cryst. A32 (1976) 751-767.

[25] E. Neau, C. Nicolas, L. Avaullée, $29^{\text {th }}$ Symposium on Applied Thermodynamics, Bucharest (Romania), 18-21 May 2017.

[26] L. Chunxi, W. Füst, Chem. Eng. Sci. 55 (2000) 2975-2988.

[27] W. Dannhauser, L.W. Bahre, J. Chem. Phys. 40(10) (1964) 3058-3066.

[28] W.M. Haynes, CRC Handbook of Chemistry and Physics, 95th edition (2014-2015).

[29] E. Neau, I. Raspo (to be submitted to Chem. Eng. Sci. 2017).

[30] X. Ji, S.P. Tan, H. Adidharma, M. Radosz, Ind. Eng. Chem. Res. 44 (2005) 8419-8427.

[31] R. Sun, J. Dubessy, Geochim. Cosmochim. Acta. 88 (2012) 130-145.

[32] S. Takenouchi, G.C. Kennedy, Am. J. Sci. 263 (1965) 445-454.

[33] A. Pérez-Salado Kamps, M. Jödecke, J. Xia, M. Vogt, G. Maurer, Ind. Eng. Chem. Res., 45 (2006) 1505-1515.

L.M.C. Pereira, A. Chapoy, R. Burgass, B.Tohidi, Advances in Water Resources 103 (2017) 6475.

[35] M. Rahmati-Rostami, B. Behzadi, C. Ghotbi, Fluid Phase Equilib. 309 (2011) 179-189.

[36] C. Held, L.F. Cameretti, G. Sadowski, Fluid Phase Equilib. 270 (2008) 87-96.

[37] P. Wang, A. Anderko, R.D. Young, Fluid Phase Equilib. 223(1) (2002) 141-176.

[38] A. Bamberger, G. Sieder, G. Maurer, J.Supercrit.Fluid 17 (2000) 95-110.

[39] R.G. Sultanov, V.G. Skripka, A.Y. Namiot, Gazov. Promst., 16 (1971) 6-8. 
[40] S. Takenouchi, G.C. Kennedy, Am. J. Sci., 262 (1964) 10055-10741.

[41] A. Chapoy, A.H. Mohammadi, B. Tohidi, D. Richon, J. Chem. Eng. Data 50 (2005) 1157-1161.

[42] R. Wiebe, V.L. Gaddy, C.J. Heins, Ind. Eng. Chem. 24 (1932) 927-930.

[43] D. Koschel, J.-Y. Coxam, V. Majer, Ind. Eng. Chem. Res. 52 (2013) 14483-14491.

[44] T.N. Kozintseva, Geochem. Int. (1964) 750-756.

C.W. Blount, L.C. Price, L.M. Wenger, M. Tarullo, Fourth United States Gulf Coast

[45] Geopressured-Geothermal Energy Conference, Research and Development 4.3 (1980) 12251262.

[46] W. Yan, S. Huang, E.H. Stenby, Int. J. Greenhouse Gas Control 5 (6) (2011) 1460-1477.

[47] S.D. Malinin, N.I. Savelyeva, Geochem. Int. 9 (1972) 410-418.

[48] S.D. Malinin, N.A. Kurovskaya, Geochem. Int. 12 (1975) 199-201.

[49] A.J. Ellis, R.M. Golding, Am. J. Sci. 261 (1963) 47-60.

[50] K. Tödheide, E.U. Franck, Z. Phys. Chem., 37 (1963) 387-401.

[51] T. O'Sullivan, N.O. Smith, J. Phys. Chem., 74 (7) (1970) 1460-1466.

[52] N.N. Akinfiev, V. Majer, Y.V. Shvarov, Chemical Geology 424 (2016) 1-11.

[53] K. Kojima, M. Kato, Kagaku Kogaku 33 (1969) 769-775.

[54] K. Kurihara, M. Nakamichi, K. Kojima, J. Chem. Eng. Data 38 (1993) 446-449.

[55] M. Kato, H. Konishi, M. Hirata, J. Chem. Eng. Data 15 (1970) 501-505.

[56] H. Nishi, E. Nagao, Wakayama Kogyo Koto Senmon Gakko Kenkyu Kiyo 25 (1990) 71-74.

[57] H. Nishi, N. Kanai, Wakayama Kogyo Koto Senmon Gakko Kenkyu Kiyo 20 (1985) 47-50.

[58] V.G. Garbarenko, V.N. Stabnikov, Phisch.Tekhnol. 4 (1960) 112.

[59] Y.S. Kim, S.K. Ryu, S.O. Yang, C.S. Lee, Ind. Eng. Chem. Res. 42 (11) (2003) 2409-2414.

[60] A. Chapoy, C. Coquelet, D. Richon, Fluid Phase Equilib., 214 (1) (2003) 101-117.

[61] O.L. Culberson, J.J. McKetta, Trans. Am. Inst. Min. Metall. Pet. Eng., 192 (1951) 223-226.

[62] R.K. Stoessell, P.A. Byrne, Geochimica et Cosmochimica Acta Vol. 46 (1982) 1321-1332.

[63] J. Kiepe, S. Horstmann, K. Fischer, J. Gmehling, Ind. Eng. Chem. Res., 42 (21) (2003) $5392-$ 5398.

[64] J.E. Davis, J.J. McKetta, Pet. Refiner, 39 (3) (1960) 205-206.

[65] R. Wiebe, V.L. Gaddy, J. Am. Chem. Soc., 61 (1939) 315-318.

[66] J. Kiepe, S. Horstmann, K. Fischer, J. Gmehling, Ind. Eng. Chem. Res. 41 (17) (2002) 4393 4398.

[67] Y. Zelvinskii, Zhum. Khim. Prom., 14 (1937) 1250-1257.

[68] J.T. Safarov, Fluid Phase Equilibria 243 (2006) 38-44.

[69] J.F. Morrison, J.C. Baker, H.C. Meredith, K.E. Newman, T.D. Walter, J.D. Massie, R.L. Perry, P.T. Cummings, J. Chem. Eng. Data 35 (1990) 395-404.

[70] A. Michels, J. Gerver, A. Biji, Physica 3 (1936) 797-808.

[71] S. Bando, F. Takemura, M. Nishio, E. Hihara, M. Akai, J. Chem. Eng. Data 48 (3) (2003) 576579.

[72] G. Ferrentino, D. Barletta, F. Donsi, G.Ferrari, M. Poletto, Ind. Eng. Chem. Res. 49 (6) (2010) 2992-3000.

[73] J. Gerecke, Diss. Dr. rer. Nat., Hochsch. "Carl Schorlemmer", Leuna-Merseburg, DDR (1969).

[74] F. Gu, Gaoxiao Huaxue Gongcheng Xuebao, 12 (2) (1998) 118-123.

[75] S.-X. Hou, G.C. Maitland, J.P.M. Trusler, J. of Supercritical Fluids 78 (2013) 78-88.

[76] D. Koschel, J.Y. Coxam, L. Rodier, V. Majer, Fluid Phase Equilib. 247 (1-2) (2006) 107-120. 
[77] A.E. Markham, K.A. Kobe, J. Am. Chem. Soc. 7 (1) (1935) 37-38.

[78] J.A. Nighswander, N. Kalogerakis, A.K. Mehrotra, J. Chem. Eng. Data 34 (1989) 355-360.

[79] B. Rumpf, H. Nicolaisen, C. Oecal, G. Maurer, J. Solution Chem. 23 (3) (1994) 431-448.

[80] V. Savary, G. Berger, M. Dubois, J.C. Lacharpagne, A. Pages, S. Thibeau, M. Lescanne, Int. J. Greenhouse Gas Control 10 (2012) 123-133.

[81] B. Tohidi, A. Danesh, R.W. Burgass, A.C. Todd, Proceedings of the Fifth (1995) International Offshore and Polar Engineering Conference. Vol. 1 pp263-268.

[82] L.S. Wang, Z.X. Lang, T.M. Guo, Fluid Phase Equilib. 117 (1996) 364-372.

[83] D.-Q. Zheng, T.-M. Guo, H. Knapp, Fluid Phase Equilibria 129 (1997) 197-209.

[84] H. Zhao, M.V. Fedkin, R.M. Dilmore, S.V. Lvov, Geo.et Cosmochimica Acta 149 (2015) 165189.

[85] T.J. Barrett, G.M. Anderson, J. Lugowski, Geochimica et Cosmochimica Acta 52 (1988) 807811.

[86] O. M. Suleimenov, R. E. Krupp, Geochimica et Cosmochimica Acta 58 (1994) 2433-2444.

[87] J. Xia, A. Kamps, B. Rumpf, G. Maurer, Ind. Eng. Chem. Res. 39 (2000) 1064-1073.

[88] I. Barthel, R. Neueder, G. Lauermann, Journal of Solution Chemistry, 14 (9) (1985) 621-633.

[89] J. Yao, H. Li, S. Han, Fluid Phase Equilib. 162 (1999) 253-260.

[90] M. Joedecke, A. Perez-Salado Kamps, G. Maurer, J. Chem. Eng. Data 50 (1) (2005) 138-141.

[91] A.I. Johnson, W.F. Furter, Can. J. Chem. Eng. 38 (1960) 78-87.

[92] J.H. Kiepe, Shaker, Aachen (2004) 1-172.

[93] S.O. Yang, C.S. Lee, J. Chem. Eng. Data 43 (4) (1998) 558-561.

[94] L.L. Dobroserdov, V.P. Ilina, Tr. Leningr. Tekhnol. Inst. Pishch. Promsti. 14 (1958) 143-146.

[95] R.S. Maizlish, I.P. Tverdovskii, Zh. Fiz. Khim. 27 (11) (1953) 1597-1603.

[96] T. Meyer, H.M. Polka, J. Gmehling, J. Chem. Eng. Data 36 (3) (1991) 340-342.

[97] H.M. Polka, Thesis Universität Oldenburg (1990) 1-81.

[98] A. Rius Miro, J.L. Otero de la Gandara, J.R.A. Gonzalez, An. R. Soc. Esp. Fis. Quim. Ser. B 53 (1957) 171-183.

[99] R. Sun, Huaxue Gongcheng 23(1) 13-17.

[100] R. Yang, J. Demirgian, J.F. Solsky, E.J. Kikta, J.A. Marinsky, J. Phys. Chem. 83 (21) (1979) 2752-2761.

[101] C.L. Lin, L.S. Lee, H.C. Tseng, J. Chem. Eng. Data 38 (2) (1993) 306-309.

[102] H. Miyakawa, , Sasebo Kogyo Koto Senmon Gakko Kenkyu Hokoku 21 (1984) 71-74. [103] E. Schreiber, E. Schuettau, D. Rant, H. Schuberth, Z. Phys. Chem. Leipzig 247 (1-2) (1971) 23-
40.

[104] R.Y. Sun, Q. Sun, Fluid Phase Equilib. 193 (2002) 135-145.

[105] H.M. Polka, Shaker, Aachen (1994) 1-144.

[106] M. Rajendran, S. Renganarayanan, D. Srinivasan, , Fluid Phase Equilib. 50 (1989) 133-164.

[107] S.D. Malinin, N.I. Savalyeva, Geokhimiya, 6 (1972) 643-653.

[108] C.F. Prutton, R.L. Savage, J. Am. Chem. Soc., 67 (1945) 1550-1554. 


\section{LIST OF TABLES}

Table 1. NRTL-PRA groups $K$ and subgroups $k$ : surface area $Q_{k}$ and volume $R_{k}$ [Ref.], stereochemistry $S_{k}$ and polarity $P_{k .}$ (*) this work, with ionic radius $\left.I r_{i o n}[24]\right)$.

Table 2a. Values (in J/mol) of the NRTL-PRA group interaction parameters $\Gamma_{L K}^{(0)}$ (oll = methanol, $o l 2=$ ethanol, $1-o l=$ primary alcohol, $2-o l=$ secondary alcohol $)$.

Table 2b. Values (in J/mol) of the NRTL-PRA group interaction parameters $\Gamma_{L K}^{(1)}$ (oll = methanol, ol2 = ethanol, $1-o l=$ primary alcohol, $2-o l=$ secondary alcohol $)$.

Table 2c. Values (in J/mol) of the NRTL-PRA group interaction parameters $\Gamma_{L K}^{(2)}($ oll $=$ methanol, $o l 2=$ ethanol, $1-o l=$ primary alcohol, 2-ol $=$ secondary alcohol) .

Table 3. Parameter values of the relative permittivity $\mathcal{E}_{r}(T)$ : CRC values at the reference temperature $T_{\text {ref }} / K$ for light gases and estimations from Eq.(19) for polar compounds.

Table 4. Correlation of VLE data for light gases and alcohols with water and NaCl. Literature data: intervals of experimental temperatures $\left(T_{\min }, T_{\max }\right.$, in Kelvin), pressures $\left(P_{\min }, P_{\max }\right.$, in bar), amount of salt introduced in the solvent $\left(m_{\min }, m_{\max }\right)$, type* of measurements and references (Ref.). Modeling: isothermal data, with number of pressures $\left(N_{P}\right)$ and deviations $(\triangle P / P \%)$; isobaric data, with number of temperatures $\left(N_{T}\right)$ and deviations $(\Delta T / T \%)$; vapor phase composition data, with number of points $\left(N_{y}\right)$ and deviations $(\Delta y / y \%)$.

type $^{*}$ : salt molality $(m)$, mole fraction of salt $(x)$

Table 5 Correlation of VLE data for light gases and alcohols with water and other salts. Literature data: intervals of experimental temperatures ( $T_{\min }, T_{\max }$, in Kelvin), pressures ( $P_{\min }, P_{\max }$, in bar), amount of salt introduced in the solvent $\left(m_{\min }, m_{\max }\right)$, type* of measurements and references (Ref.). Modeling: isothermal data, with number of pressures $\left(N_{P}\right)$ and deviations $(\triangle P / P \%)$; isobaric data, with number of temperatures $\left(N_{T}\right)$ and deviations $(\Delta T / T \%)$; vapor phase composition data, with number of points $\left(N_{y}\right)$ and deviations $(\Delta y / y \%)$.

type $^{*}$ : salt molality $(m)$, mole fraction of salt $(x)$

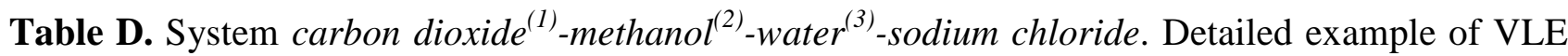
calculations at a given temperature and salt concentration : $T=313.66 \mathrm{~K}, \rho=0.049, m_{s}=1.74 \mathrm{~mol} \cdot \mathrm{kg}^{-}$ 1; ions: $\mathrm{Na}^{+(4)}$ and $\mathrm{Cl}^{-(5)}$. 


\section{FIGURES CAPTIONS}

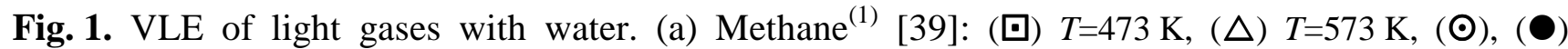
$T=603 \mathrm{~K},(\diamond) T=625 \mathrm{~K},(\nabla),(\boldsymbol{\nabla}) T=633 \mathrm{~K}$. (b) Carbon dioxide ${ }^{(1)}[40]:(\square) T=543 \mathrm{~K},(\triangle) T=548 \mathrm{~K},(\odot)$ $T=573 \mathrm{~K},(\diamond) T=598 \mathrm{~K},(\nabla) T=623 \mathrm{~K}$. (c) Nitrogen ${ }^{(1)}$ : (田 $T=278 \mathrm{~K}[41],(\triangle) T=288 \mathrm{~K}[41],(\odot) T=293 \mathrm{~K}$

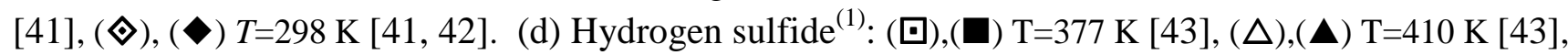

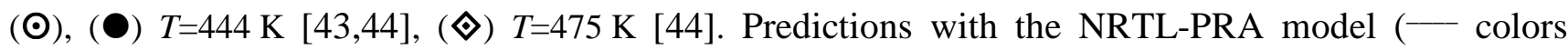
correspond to symbols).

Fig. 2. Relative permittivity $\varepsilon_{r}$ with respect to temperature: (a) $\mathrm{H}_{2} \mathrm{O}$ and (b) methanol. Calculations: $(-)$ this work, (- literature (a) [26], (b) [27], (-) CRC tables [28]. Limit of the experimental domain $\left(^{--}\right)$[28].

Fig. 3. VLE of methane ${ }^{(1)}-$ water $^{(2)}$ with sodium chloride [45] at $408 \mathrm{~K}$ for various molalities $m_{0}$. (a) : (回) $m_{0}=0.00 \mathrm{~mol} \cdot \mathrm{kg}^{-1},(\triangle),(\mathbf{\Delta}) m_{0}=0.85 \mathrm{~mol} \cdot \mathrm{kg}^{-1},(\odot),(\bullet) m_{0}=1.70 \mathrm{~mol} \cdot \mathrm{kg}^{-1},(\diamond),(\diamond),(*)$, $m_{0}=2.50 \mathrm{~mol} \cdot \mathrm{kg}^{-1}$. (b): (回), (品), (*) $m_{0}=3.40 \mathrm{~mol} \cdot \mathrm{kg}^{-1},(\Delta),(\boldsymbol{\Delta}),(\boldsymbol{*}),(\mathbf{X}),(\boldsymbol{+}) m_{0}=4.20 \mathrm{~mol} \cdot \mathrm{kg}^{-1}$. Predictions with the NRTL-PRA model (— colors correspond to symbols).

(c): eCPA representation [3].

Fig. 4. VLE of carbon dioxide $\mathrm{e}^{(1)}-$ water $^{(2)}$ with sodium chloride. (a) $\mathrm{NaCl}$ molality $m_{0}=1.00 \mathrm{~mol} \cdot \mathrm{kg}^{-1}$

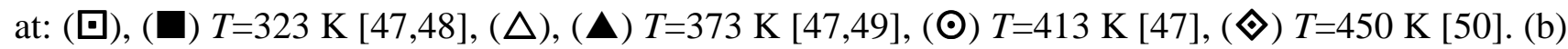
$T=572 \mathrm{~K}$ for: $(\square),(\boldsymbol{\square}) m_{0}=0.00 \mathrm{~mol} \cdot \mathrm{kg}^{-1}[40,50],(\triangle) m_{0}=1.03 \mathrm{~mol} \cdot \mathrm{kg}^{-1}$ [40]. Predictions with the NRTL-PRA model (- colors correspond to symbols).

(c): eCPA representation [3].

Fig. 5. VLE of (a) nitrogen ${ }^{(1)}-$ water $^{(2)}$ and (b) hydrogen sulfide ${ }^{(1)}-$ water $^{(2)}$ with sodium chloride.

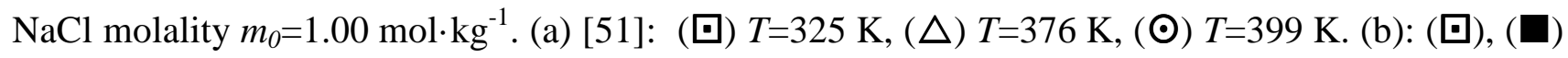
$T=323 \mathrm{~K}[52,43],(\triangle) T=373 \mathrm{~K}[52],(\odot) T=423 \mathrm{~K}[52],(\diamond) T=473 \mathrm{~K}$ [52]. Calculations with the NRTL-PRA model (— colors correspond to symbols).

Fig. 6. VLE of (a) methanol ${ }^{(1)}-$ water $^{(2)}$ and (b) ethanol ${ }^{(1)}-$ water $^{(2)}$ with sodium chloride at 1.01 bar

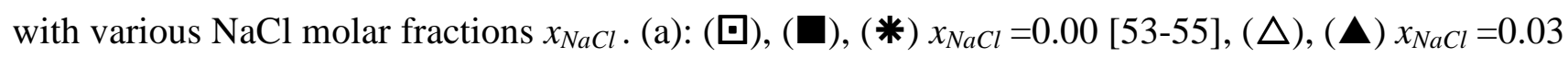

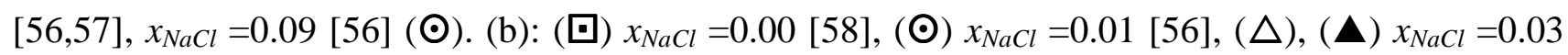
$[56,57]$. Calculations with the NRTL-PRA model (— colors correspond to symbols).

Fig. 7. VLE of carbon dioxide ${ }^{(1)}-$ methanol $^{(2)}-$ water $^{(3)}$ with sodium chloride. Data of Pérez-Salado Kamps et al. [33] at: (回) $T=314 \mathrm{~K},(\triangle) T=354 \mathrm{~K}$, (๑) $T=395 \mathrm{~K}$ for various solute-free solvent mixture composition $\rho$ and molalities $m_{s}$. (a) $\rho=0.049, m_{s}=1.74 \mathrm{~mol} \cdot \mathrm{kg}^{-1}$. (b) $\rho=0.750, m_{s}=0.25$ $\mathrm{mol} \cdot \mathrm{kg}^{-1}$. Predictions with the NRTL-PRA model (— colors correspond to symbols).

Fig. 8. VLE of methane ${ }^{(1)}-$ water $^{(2)}$ with: (a) $\mathrm{MgCl}_{2}$ and (b) $\mathrm{LiCl}$, for various molalities $m_{0}$. (a)

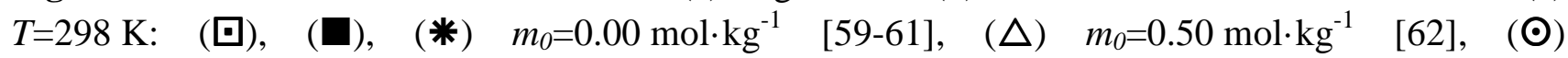

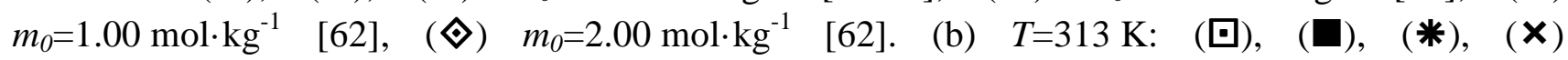
$m_{0}=0.00 \mathrm{~mol} \cdot \mathrm{kg}^{-1}[63,60,59,64],(\triangle) m_{0}=2.49 \mathrm{~mol} \cdot \mathrm{kg}^{-1} \quad[62],(\odot) m_{0}=4.99 \mathrm{~mol} \cdot \mathrm{kg}^{-1} \quad[62],(\diamond)$ $m=7.99 \mathrm{~mol} \cdot \mathrm{kg}^{-1}$ [62]. Calculations with the NRTL-PRA model (— colors correspond to symbols). 
Fig. 9. VLE of carbon dioxide ${ }^{(1)}-$ water $^{(2)}$ with: (a) $\mathrm{KCl}$ and (b) $\mathrm{CaCl}_{2}$ for various molalities $m_{0}$. (a)

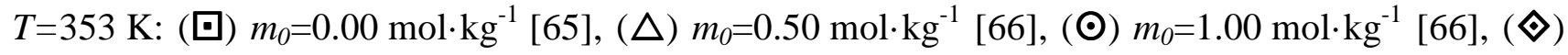

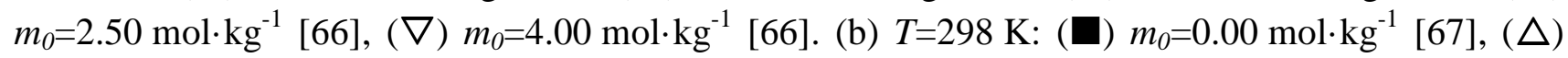

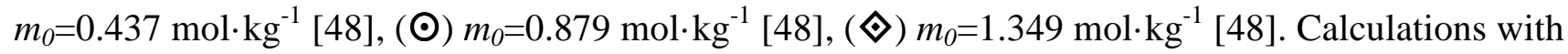
the NRTL-PRA model (— colors correspond to symbols).

Fig10. VLE of: (a) ethanol ${ }^{(1)}$-water ${ }^{(2)}$ with $\mathrm{LiBr}$ and (b) 1-propanol ${ }^{(1)}-$ - $_{\text {ater }}{ }^{(2)}$ with $\mathrm{KBr}$, for variable values molalities $m_{0}$. (a) Comparison of predicted pressures with experimental data [68] at: ( $\square$ ) $T=298.15 \mathrm{~K}$, (O) $T=303.15 \mathrm{~K},(\triangle) T=308.15 \mathrm{~K},(\diamond) T=313.15 \mathrm{~K}$, (*) $T=318.15 \mathrm{~K}$. (b) Comparison of predicted temperatures with experimental data [69] under $\mathrm{P}=1.01$ bar. Calculations with the NRTL-PRA model. 


\section{Table 1}

NRTL-PRA groups $K$ and subgroups $k$ : surface area $Q_{k}$ and volume $R_{k}\left[R e f\right.$.], stereochemistry $S_{k}$ and polarity $P_{k}$. (*) this work, with ionic radius $I r_{i o n}$ [24]).

\begin{tabular}{|c|c|c|c|c|c|c|c|}
\hline$K$ & $k$ & $Q_{k}$ & $R_{k}$ & $S_{k}$ & $P_{k}$ & Ref. & $I r_{i o n}(p m)$ \\
\hline \multirow{4}{*}{ Paraffin (PAR) } & $\mathrm{CH}_{3}$ & 0.848 & 0.901 & 2.80 & 0.0 & [21] & \\
\hline & $\mathrm{CH}_{2}$ & 0.540 & 0.674 & 2.00 & 0.0 & {$[21]$} & \\
\hline & $\mathrm{CH}$ & 0.228 & 0.447 & -5.65 & 0.0 & {$[21]$} & \\
\hline & $\mathrm{C}$ & 0.000 & 0.220 & -5.65 & 0.0 & {$[21]$} & \\
\hline Methane $\left(\mathbf{C H}_{4}\right)$ & $\mathrm{CH}_{4}$ & 1.124 & 1.129 & 1.17 & 0.0 & {$[22]$} & \\
\hline Carbon dioxide $\left(\mathbf{C O}_{2}\right)$ & $\mathrm{CO}_{2}$ & 0.982 & 1.300 & 1.00 & 0.0 & {$[22]$} & \\
\hline Nitrogen $\left(\mathbf{N}_{2}\right)$ & $\mathrm{N}_{2}$ & 0.930 & 0.856 & 1.00 & 0.0 & {$[22]$} & \\
\hline Hydrogen sulfide $\left(\mathbf{H}_{2} \mathbf{S}\right)$ & $\mathrm{H}_{2} \mathrm{~S}$ & 1.202 & 1.235 & 1.00 & 0.0 & {$[22]$} & \\
\hline Water $\left(\mathbf{H}_{2} \mathbf{O}\right)$ & $\mathrm{H}_{2} \mathrm{O}$ & 1.400 & 0.920 & 1.00 & 1.0 & {$[21]$} & \\
\hline Alcohol $(\mathbf{O H})$ & $\mathrm{OH}$ & 1.152 & 1.270 & 1.00 & 1.0 & {$[21]$} & \\
\hline Sodium cation $\left(\mathbf{N a}^{+}\right)$ & $\mathrm{Na}^{+}$ & 0.360 & 0.400 & 1.00 & 1.0 & $*$ & 99 \\
\hline Magnesium cation $\left(\mathbf{M g}^{2+}\right)$ & $\mathrm{Mg}^{2+}$ & 0.245 & 0.274 & 1.00 & 1.0 & $*$ & 65 \\
\hline Calcium cation $\left(\mathbf{C a}^{2+}\right)$ & $\mathrm{Ca}^{2+}$ & 0.375 & 0.417 & 1.00 & 1.0 & $*$ & 99 \\
\hline Potassium cation $\left(\mathbf{K}^{+}\right)$ & $\mathrm{K}^{+}$ & 0.500 & 0.560 & 1.00 & 1.0 & $*$ & 133 \\
\hline Lithium cation $\left(\mathbf{L i}^{+}\right)$ & $\mathrm{Li}^{+}$ & 0.230 & 0.250 & 1.00 & 1.0 & $*$ & 60 \\
\hline Chlorine anion $\left(\mathrm{Cl}^{-}\right)$ & $\mathrm{Cl}^{-}$ & 0.720 & 0.790 & 1.00 & 1.0 & $*$ & 181 \\
\hline Bromine anion $\left(\mathbf{B r}^{-}\right)$ & $\mathrm{Br}^{-}$ & 0.780 & 0.850 & 1.00 & 1.0 & $*$ & 195 \\
\hline
\end{tabular}




\section{Table 2a}

Values (in J/mol) of the NRTL-PRA group interaction parameters $\Gamma_{L K}^{(0)}(o l l=$ methanol, ol2 = ethanol, 1 -ol $=$ primary alcohol, $2-o l=$ secondary alcohol $)$.

\begin{tabular}{|c|c|c|c|c|c|c|c|c|c|c|}
\hline $\mathbf{L} \backslash \mathbf{K}$ & PAR & $\mathrm{CH}_{4}$ & $\mathrm{CO}_{2}$ & $\mathbf{N}_{2}$ & $\mathbf{H}_{2} \mathrm{~S}$ & $\mathrm{H}_{2} \mathrm{O}$ & $\begin{array}{c}\mathbf{O H} \\
(\text { oll })\end{array}$ & $\begin{array}{c}\mathbf{O H} \\
(\text { ol } 2)\end{array}$ & $\begin{array}{c}\mathbf{O H} \\
(1-o l)\end{array}$ & $\begin{array}{c}\mathbf{O H} \\
(2-o l)\end{array}$ \\
\hline PAR & 0.00 & 147.46 & 866.64 & 523.57 & 733.34 & 2398.94 & * & 4521.85 & 4413.07 & 4413.07 \\
\hline $\mathrm{CH}_{4}$ & 147.46 & 0.00 & 748.07 & 231.80 & 1016.15 & 2306.71 & 1309.96 & - & - & - \\
\hline $\mathrm{CO}_{2}$ & 866.64 & 748.07 & 0.00 & 743.75 & 743.35 & 2109.97 & 883.70 & - & - & - \\
\hline $\mathbf{N}_{2}$ & 523.57 & 231.80 & 743.75 & 0.00 & 1670.18 & 2503.54 & 2332.57 & - & - & - \\
\hline $\mathrm{H}_{2} \mathrm{~S}$ & 733.34 & 1016.15 & 743.35 & 1670.18 & 0.00 & 1931.51 & -24948.45 & - & - & - \\
\hline $\mathrm{H}_{2} \mathrm{O}$ & 3245.43 & 3369.09 & 2497.88 & 3443.88 & 2267.08 & 0.00 & -1200.31 & 2561.45 & 2918.87 & 2843.36 \\
\hline $\mathbf{O H}($ oll $)$ & $*$ & 1880.11 & 729.89 & 2092.99 & 1434.23 & -620.11 & 0.00 & - & - & - \\
\hline $\mathbf{O H}($ ol2 $)$ & 2932.98 & - & - & - & - & -1422.14 & - & 0.00 & - & - \\
\hline $\mathbf{O H}(1-o l)$ & 3460.73 & - & - & - & - & -969.98 & - & - & 0.00 & - \\
\hline $\mathbf{O H}(2-o l)$ & 3460.73 & - & - & - & - & -1075.32 & - & - & - & 0.00 \\
\hline $\mathrm{Na}^{+}$ & - & 6705.82 & 6232.45 & 5884.86 & 4754.60 & 0.00 & 4502.32 & 10617.77 & 17632.54 & 18943.19 \\
\hline $\mathrm{Mg}^{2+}$ & - & 6621.06 & - & - & - & 0.00 & - & - & - & - \\
\hline $\mathrm{Ca}^{2+}$ & - & -8554.58 & 10046.34 & - & - & 0.00 & - & - & - & - \\
\hline $\mathbf{K}^{+}$ & - & -1800.00 & 4329.42 & - & - & 0.00 & - & - & 18593.51 & - \\
\hline $\mathbf{L i}^{+}$ & - & -1600.00 & - & - & - & 0.00 & - & -11213.68 & - & - \\
\hline $\mathrm{Cl}^{-}$ & - & 6727.03 & 5906.65 & 6401.88 & 5382.62 & 0.00 & 4502.32 & 10617.77 & 17632.54 & 18943.19 \\
\hline $\mathrm{Br}^{-}$ & - & 6131.77 & - & - & - & 0.00 & - & 8727.83 & 18593.51 & - \\
\hline
\end{tabular}

$\Gamma^{(0)} \mathrm{OH}^{*} / \mathrm{CH} 3=\quad 1535.09 \quad \Gamma^{(0)} \mathrm{CH}_{3} / \mathrm{OH}^{*}=\quad-235.94$

$\Gamma^{(0)} \mathrm{OH}^{*} / \mathrm{CH} 2=2185.15 \quad \Gamma^{(0)} \mathrm{CH}_{2} / \mathrm{OH}^{*}=\quad 2220.91$ 
Table 2a (continued)

\begin{tabular}{|c|c|c|c|c|c|c|c|}
\hline $\mathbf{L} \backslash \mathbf{K}$ & $\mathrm{Na}^{+}$ & $\mathrm{Mg}^{2+}$ & $\mathrm{Ca}^{2+}$ & $\mathbf{K}^{+}$ & $\mathbf{L i}^{+}$ & $\mathrm{Cl}^{-}$ & $\mathrm{Br}^{-}$ \\
\hline PAR & - & - & - & - & - & - & - \\
\hline $\mathrm{CH}_{4}$ & 6705.85 & 6621.09 & 6419.95 & -1800.00 & -1600.00 & 6727.03 & 6131.77 \\
\hline $\mathrm{CO}_{2}$ & 6087.69 & - & 9554.02 & 4329.42 & - & 4989.75 & - \\
\hline $\mathbf{N}_{2}$ & 5884.86 & - & - & - & - & 6401.88 & - \\
\hline $\mathrm{H}_{2} \mathrm{~S}$ & 4754.60 & - & - & - & - & 5382.62 & - \\
\hline $\mathbf{H}_{2} \mathbf{O}$ & 0.00 & 0.00 & 0.00 & 0.00 & 0.00 & 0.00 & 0.00 \\
\hline $\mathbf{O H}($ oll $)$ & 3951.48 & - & - & - & - & 3951.48 & - \\
\hline $\mathbf{O H}($ ol2 $)$ & 6544.03 & - & - & - & -15287.46 & 6544.03 & 4654.09 \\
\hline $\mathbf{O H}(1-o l)$ & 12703.74 & - & - & 13664.72 & - & 12703.74 & 13664.72 \\
\hline $\mathbf{O H}(2-o l)$ & 14018.23 & - & - & - & - & 14018.23 & - \\
\hline $\mathrm{Na}^{+}$ & 0.00 & 0.00 & 0.00 & 0.00 & 0.00 & 0.00 & 0.00 \\
\hline $\mathrm{Mg}^{2+}$ & 0.00 & 0.00 & 0.00 & 0.00 & 0.00 & 0.00 & 0.00 \\
\hline $\mathrm{Ca}^{2+}$ & 0.00 & 0.00 & 0.00 & 0.00 & 0.00 & 0.00 & 0.00 \\
\hline $\mathbf{K}^{+}$ & 0.00 & 0.00 & 0.00 & 0.00 & 0.00 & 0.00 & 0.00 \\
\hline $\mathbf{L i}^{+}$ & 0.00 & 0.00 & 0.00 & 0.00 & 0.00 & 0.00 & 0.00 \\
\hline $\mathrm{Cl}^{-}$ & 0.00 & 0.00 & 0.00 & 0.00 & 0.00 & 0.00 & 0.00 \\
\hline $\mathrm{Br}^{-}$ & 0.00 & 0.00 & 0.00 & 0.00 & 0.00 & 0.00 & 0.00 \\
\hline
\end{tabular}




\section{Table 2b}

Values (in J/mol) of the NRTL-PRA group interaction parameters $\Gamma_{L K}^{(1)}(o l l=$ methanol, ol2 = ethanol, 1 -ol= primary alcohol, 2 -ol $=$ secondary alcohol).

\begin{tabular}{|c|c|c|c|c|c|c|c|c|c|c|}
\hline $\mathbf{L} \backslash \mathbf{K}$ & PAR & $\mathrm{CH}_{4}$ & $\mathrm{CO}_{2}$ & $\mathbf{N}_{2}$ & $\mathrm{H}_{2} \mathrm{~S}$ & $\mathrm{H}_{2} \mathrm{O}$ & $\begin{array}{c}\mathbf{O H} \\
(\text { oll }) \\
\end{array}$ & $\begin{array}{c}\mathbf{O H} \\
(\text { ol } 2) \\
\end{array}$ & $\begin{array}{c}\mathbf{O H} \\
(1-\mathrm{ol}) \\
\end{array}$ & $\begin{array}{c}\mathbf{O H} \\
(2-o l) \\
\end{array}$ \\
\hline PAR & 0.00 & 13.31 & 609.92 & 59.69 & -227.72 & -3417.62 & * & -5087.56 & -6467.13 & -6467.15 \\
\hline $\mathrm{CH}_{4}$ & 13.31 & 0.00 & 308.54 & -4.30 & -166.44 & -3717.59 & -5857.32 & - & - & - \\
\hline $\mathrm{CO}_{2}$ & 609.92 & 308.54 & 0.00 & 165.41 & -368.65 & -4221.74 & -10885.41 & - & - & - \\
\hline $\mathbf{N}_{2}$ & 59.69 & -4.30 & 165.41 & 0.00 & -171.30 & -5321.74 & -3933.10 & - & - & - \\
\hline $\mathbf{H}_{2} \mathrm{~S}$ & -227.72 & -166.44 & -368.65 & -171.30 & 0.00 & -2304.83 & -26517.61 & - & - & - \\
\hline $\mathrm{H}_{2} \mathrm{O}$ & -294.87 & -896.83 & -504.59 & -1150.55 & -1155.40 & 0.00 & -1232.08 & -4461.58 & -6350.58 & -5370.02 \\
\hline $\mathbf{O H}($ oll $)$ & $*$ & 3503.52 & 10140.97 & 702.87 & -963.83 & -2731.35 & 0.00 & - & - & - \\
\hline $\mathbf{O H}($ ol2 $)$ & -2016.20 & - & - & - & - & -2818.76 & - & 0.00 & - & - \\
\hline $\mathbf{O H}(1-o l)$ & -470.23 & - & - & - & - & -1115.52 & - & - & 0.00 & - \\
\hline $\mathbf{O H}(2-o l)$ & -470.23 & - & - & - & - & -2112.07 & - & - & - & 0.00 \\
\hline $\mathrm{Na}^{+}$ & - & 19877.62 & -12350.30 & -9540.70 & -7309.49 & 0.00 & -17960.41 & -10378.43 & -4342.61 & -4339.23 \\
\hline $\mathbf{M g}^{2+}$ & - & 0.00 & - & - & - & 0.00 & - & - & - & - \\
\hline $\mathrm{Ca}^{2+}$ & - & 0.00 & 44978.06 & - & - & 0.00 & - & - & - & - \\
\hline $\mathbf{K}^{+}$ & - & 0.00 & -786.88 & - & - & 0.00 & - & - & -4342.61 & - \\
\hline $\mathbf{L i}^{+}$ & - & 0.00 & - & - & - & 0.00 & - & -3881.90 & - & - \\
\hline $\mathrm{Cl}^{-}$ & - & 20333.42 & -11304.57 & -10224.46 & -8571.65 & 0.00 & -17960.41 & -10378.43 & -4342.61 & -4339.23 \\
\hline $\mathrm{Br}^{-}$ & - & 19860.67 & - & - & - & 0.00 & - & -3881.90 & -4342.61 & - \\
\hline
\end{tabular}

$\begin{array}{llll}\Gamma^{(1)} \mathrm{OH}^{*} / \mathrm{CH} 3= & 2629.81 & \Gamma^{(1)} \mathrm{CH}_{3 / \mathrm{OH}^{*}}= & -6159.54 \\ \Gamma^{(1)} \mathrm{OH}^{* / C H 2}= & -37.35 & \Gamma^{(1)} \mathrm{CH}_{2} / \mathrm{OH}^{*}= & -92.72\end{array}$


Table 2b (continued)

\begin{tabular}{cccccccc}
\hline $\mathbf{L I K}$ & $\mathbf{N a}^{+}$ & $\mathbf{M g}^{2+}$ & $\mathbf{C a}^{2+}$ & $\mathbf{K}^{+}$ & $\mathbf{L i}^{+}$ & $\mathbf{C l}^{-}$ & $\mathbf{B r}^{-}$ \\
\hline $\mathbf{P A R}$ & - & - & - & - & - & - & - \\
$\mathbf{C H}_{\mathbf{4}}$ & 19877.62 & 0.00 & 0.00 & 0.00 & 0.00 & 20333.42 & 19860.67 \\
$\mathbf{C O}$ & -10489.43 & - & -2115.86 & -786.88 & - & -9231.38 & - \\
$\mathbf{N}_{2}$ & -9540.70 & - & - & - & - & -10224.46 & - \\
$\mathbf{H}_{2} \mathbf{S}$ & -7309.49 & - & - & - & - & -8571.65 & - \\
$\mathbf{H} \mathbf{O}$ & 0.00 & 0.00 & 0.00 & 0.00 & 0.00 & 0.00 & 0.00 \\
$\mathbf{O H}($ oll $)$ & -16493.06 & - & - & - & - & -16493.06 & - \\
$\mathbf{O H}($ ol2 $)$ & -6496.54 & - & - & - & 0.00 & -6496.54 & 0.00 \\
$\mathbf{O H}(1-$ ol $)$ & 0.00 & - & - & 0.00 & - & 0.00 & 0.00 \\
$\mathbf{O H}(2-$ ol $)$ & 0.00 & - & - & - & - & 0.00 & - \\
$\mathbf{N a}$ & 0.00 & 0.00 & 0.00 & 0.00 & 0.00 & 0.00 & 0.00 \\
$\mathbf{M g}^{2+}$ & 0.00 & 0.00 & 0.00 & 0.00 & 0.00 & 0.00 & 0.00 \\
$\mathbf{C a}{ }^{2+}$ & 0.00 & 0.00 & 0.00 & 0.00 & 0.00 & 0.00 & 0.00 \\
$\mathbf{K}^{+}$ & 0.00 & 0.00 & 0.00 & 0.00 & 0.00 & 0.00 & 0.00 \\
$\mathbf{L i}^{+}$ & 0.00 & 0.00 & 0.00 & 0.00 & 0.00 & 0.00 & 0.00 \\
$\mathbf{C l}^{-}$ & 0.00 & 0.00 & 0.00 & 0.00 & 0.00 & 0.00 & 0.00 \\
$\mathbf{B r}^{-}$ & 0.00 & 0.00 & 0.00 & 0.00 & 0.00 & 0.00 & 0.00 \\
\hline
\end{tabular}




\section{Table 2c}

Values (in J/mol) of the NRTL-PRA group interaction parameters $\Gamma_{L K}^{(2)}(o l l=$ methanol, ol2 $=$ ethanol, 1 -ol $=$ primary alcohol, 2 -ol $=$ secondary alcohol $)$.

\begin{tabular}{|c|c|c|c|c|c|c|c|c|c|c|}
\hline $\mathbf{L} \backslash \mathbf{K}$ & PAR & $\mathrm{CH}_{4}$ & $\mathrm{CO}_{2}$ & $\mathbf{N}_{2}$ & $\mathbf{H}_{2} \mathrm{~S}$ & $\mathrm{H}_{2} \mathrm{O}$ & $\begin{array}{c}\mathbf{O H} \\
(\text { oll }) \\
\end{array}$ & $\begin{array}{c}\mathbf{O H} \\
(\mathrm{ol} 2) \\
\end{array}$ & $\begin{array}{c}\mathbf{O H} \\
(1-\mathrm{ol}) \\
\end{array}$ & $\begin{array}{c}\mathbf{O H} \\
(2-o l) \\
\end{array}$ \\
\hline PAR & 0.00 & 0.00 & 0.00 & 0.00 & 0.00 & 0.00 & 0.00 & 0.00 & 0.00 & 0.00 \\
\hline $\mathrm{CH}_{4}$ & 0.00 & 0.00 & 0.00 & 0.00 & 0.00 & 0.00 & 0.00 & - & - & - \\
\hline $\mathrm{CO}_{2}$ & 0.00 & 0.00 & 0.00 & 0.00 & 0.00 & -309.72 & 0.00 & - & - & - \\
\hline $\mathbf{N}_{2}$ & 0.00 & 0.00 & 0.00 & 0.00 & & -320.07 & 0.00 & - & - & - \\
\hline $\mathbf{H}_{2} \mathrm{~S}$ & 0.00 & 0.00 & 0.00 & 0.00 & 0.00 & -277.57 & 0.00 & - & - & - \\
\hline $\mathrm{H}_{2} \mathrm{O}$ & 0.00 & 0.00 & -465.81 & -389.92 & -319.08 & 0.00 & -600.00 & -534.28 & -1037.78 & -5370.02 \\
\hline $\mathbf{O H}($ oll $)$ & 0.00 & 0.00 & 0.00 & 0.00 & 0.00 & -370.03 & 0.00 & - & - & - \\
\hline $\mathbf{O H}($ ol2 $)$ & 0.00 & - & - & - & - & -539.32 & - & 0.00 & - & - \\
\hline $\mathbf{O H}(1-o l)$ & 0.00 & - & - & - & - & -518.21 & - & - & 0.00 & - \\
\hline $\mathbf{O H}(2-o l)$ & 0.00 & - & - & - & - & -527.76 & - & - & - & 0.00 \\
\hline $\mathrm{Na}^{+}$ & - & 19778.56 & -190.28 & 0.00 & 0.00 & 0.00 & 0.00 & 0.00 & 0.00 & 0.00 \\
\hline $\mathbf{M g}^{2+}$ & - & 0.00 & - & - & - & 0.00 & - & - & - & - \\
\hline $\mathrm{Ca}^{2+}$ & - & 0.00 & 44978.09 & - & - & 0.00 & - & - & - & - \\
\hline $\mathbf{K}^{+}$ & - & 0.00 & 8865.67 & - & - & 0.00 & - & - & 0.00 & - \\
\hline $\mathbf{L i}^{+}$ & - & 0.00 & - & - & - & 0.00 & - & 0.00 & - & - \\
\hline $\mathrm{Cl}^{-}$ & - & 20600.39 & 208.56 & 0.00 & 0.00 & 0.00 & 0.00 & 0.00 & 0.00 & 0.00 \\
\hline $\mathrm{Br}^{-}$ & - & 23100.96 & - & - & - & 0.00 & - & 0.00 & 0.00 & - \\
\hline
\end{tabular}


Table 2c (continued)

\begin{tabular}{cccccccc}
\hline $\mathbf{L} \mathbf{K}$ & $\mathbf{N a}^{+}$ & $\mathbf{M g}^{2+}$ & $\mathbf{C a}^{2+}$ & $\mathbf{K}^{+}$ & $\mathbf{L i}^{+}$ & $\mathbf{C l}^{-}$ & $\mathbf{B r}^{-}$ \\
\hline $\mathbf{P A R}$ & - & - & - & - & - & - & - \\
$\mathbf{C H}$ & 19778.56 & 0.00 & 0.00 & 0.00 & 0.00 & 20600.39 & 23100.96 \\
$\mathbf{C O}$ & -551.04 & - & 9442.68 & 8865.67 & - & -666.11 & - \\
$\mathbf{N}_{2}$ & 0.00 & - & - & - & - & 0.00 & - \\
$\mathbf{H}_{2} \mathbf{S}$ & 0.00 & - & - & - & - & 0.00 & - \\
$\mathbf{H}_{2} \mathbf{O}$ & 0.00 & 0.00 & 0.00 & 0.00 & 0.00 & 0.00 & 0.00 \\
$\mathbf{O H}($ oll $)$ & 0.00 & - & - & - & - & 0.00 & - \\
$\mathbf{O H}($ ol2 $)$ & 0.00 & - & - & - & 0.00 & 0.00 & 0.00 \\
$\mathbf{O H}(1-$ ol $)$ & 0.00 & - & - & 0.00 & - & 0.00 & 0.00 \\
$\mathbf{O H}(2-$ ol) & 0.00 & - & - & - & - & 0.00 & - \\
& 0.00 & 0.00 & 0.00 & 0.00 & 0.00 & 0.00 & 0.00 \\
$\mathbf{H a}^{+}$ & & & & & & & 0.00 \\
$\mathbf{M g}^{2+}$ & 0.00 & 0.00 & 0.00 & 0.00 & 0.00 & 0.00 & 0.00 \\
$\mathbf{C a}^{2+}$ & 0.00 & 0.00 & 0.00 & 0.00 & 0.00 & 0.00 & 0.00 \\
$\mathbf{K}^{+}$ & 0.00 & 0.00 & 0.00 & 0.00 & 0.00 & 0.00 & 0.00 \\
$\mathbf{L i}^{+}$ & 0.00 & 0.00 & 0.00 & 0.00 & 0.00 & 0.00 & 0.00 \\
$\mathbf{C l}^{-}$ & 0.00 & 0.00 & 0.00 & 0.00 & 0.00 & 0.00 & 0.00 \\
$\mathbf{B r}^{-}$ & 0.00 & 0.00 & 0.00 & 0.00 & 0.00 & 0.00 & 0.00 \\
\hline
\end{tabular}




\section{Table 3}

Parameter values of the relative permittivity $\mathcal{E}_{r}(T)$ : CRC values at the reference temperature $T_{r e f} / K$ for light gases and estimations from Eq.(19) for polar compounds.

\begin{tabular}{lcccccc}
\hline \multicolumn{1}{c}{ Components } & $A$ & $B$ & $C$ & $D$ & $E$ & $T_{\text {ref }} / K$ \\
\hline Light gases & & & & & & \\
$\quad$ Methane & 1.00 & 0.00 & 0.00 & 0.00 & 0.00 & 93.15 \\
Carbon dioxide & 1.50 & 0.00 & 0.00 & 0.00 & 0.00 & 295.00 \\
Nitrogen & 1.50 & 0.00 & 0.00 & 0.00 & 0.00 & 63.15 \\
Hydrogen sulfide & 5.90 & 0.00 & 0.00 & 0.00 & 0.00 & 283.51 \\
Polar compounds & & & & & & \\
Water & 5154.40 & 2.44666 & -0.00095 & -83627.21 & -954.98 & \\
Methanol & 2808.69 & 1.49172 & -0.00063 & -42566.65 & -530.44 & \\
Ethanol & -288.24 & -0.06543 & 0.000012 & 18909.83 & 47.07 & \\
1-Propanol & 2816.96 & 1.27803 & -0.000463 & -52163.46 & -519.83 & \\
2-Propanol & 2299.49 & 1.10833 & -0.000413 & -37195.05 & 429.93 & \\
\hline
\end{tabular}


Table 4

Correlation of VLE data for light gases and alcohols with water and NaCl. Literature data: intervals of experimental temperatures ( $T_{\min }, T_{\max }$, in Kelvin),

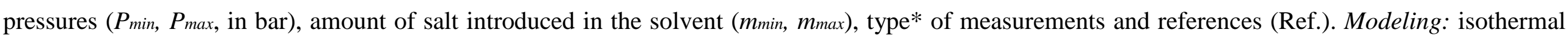
data, with number of pressures $\left(N_{P}\right)$ and deviations $(\triangle P / P \%)$; isobaric data, with number of temperatures $\left(N_{T}\right)$ and deviations $(\Delta T / T \%)$; vapor phase composition data, with number of points $\left(N_{y}\right)$ and deviations $(\Delta y / y \%)$.

type ${ }^{*}$ : salt molality $(m)$, mole fraction of salt $(x)$

\begin{tabular}{lccccccccccc}
\hline \multicolumn{1}{c}{ Components } & $T_{\min }-T_{\max }$ & $P_{\min }-P_{\max }$ & $m_{\min }-m_{\max }$ & type & $R e f$. & $N_{P}$ & $\Delta P / P \%$ & $N T$ & $\Delta T / T \%$ & $N y$ & $\Delta y / y \%$ \\
\hline Light gases & & & & & & & & & & \\
$\quad$ Methane & $298-513$ & $24-70$ & $0-5$ & $m$ & {$[45,51,62,70]$} & 179 & 29.40 & - & - & - \\
Carbon dioxide & $268-537$ & $0-400$ & $0-6$ & $m$ & {$[46-49,66,71-82]$} & 518 & 15.54 & 68 & 9.29 & 36 & 0.64 \\
Nitrogen & $323-353$ & $101-616$ & $1-4$ & $m$ & {$[51]$} & 33 & 8.30 & - & - & - & - \\
Hydrogen sulfide & $298-573$ & $1-400$ & $0-6$ & $m$ & {$[43,52,85-87]$} & 233 & 16.41 & 277 & 2.31 & 10 & 24.72 \\
Alcohols & & & & & & & & & \\
Methanol & $298-397$ & $0-5$ & $0-7$ & $m$ & {$[69,88-93]$} & 172 & 3.16 & 14 & 0.27 & 131 & 6.64 \\
& $342-373$ & 1 & $0.03-0.09$ & $x$ & {$[56,57]$} & - & - & 17 & 0.42 & 17 & 6.28 \\
Ethanol & $298-367$ & $0-1$ & $0-1$ & $m$ & {$[94-100]$} & 31 & 6.06 & 101 & 0.94 & - \\
& $306-367$ & 1 & $0.01-0.05$ & $x$ & {$[56,57]$} & - & - & 23 & 0.96 & 124 & 12.51 \\
1-Propanol & $333-382$ & $0-1$ & $0-7$ & $m$ & {$[91,101-104]$} & 15 & 5.62 & 53 & 0.35 & 41 & 13.16 \\
2-Propanol & $353-363$ & $0-1$ & $0-6$ & $m$ & {$[105,106]$} & - & - & 62 & 0.56 & 42 & 22.31 \\
\hline
\end{tabular}


Table 5.

Correlation of VLE data for light gases and alcohols with water and other salts. Literature data: intervals of experimental temperatures ( $T_{m i n}, T_{m a x}$, in Kelvin), pressures ( $P_{\min }, P_{\max }$, in bar), amount of salt introduced in the solvent ( $\left.\boldsymbol{m}_{\min }, \boldsymbol{m}_{\max }\right)$, type* of measurements and references (Ref.). Modeling: isothermal data, with number of pressures $\left(N_{P}\right)$ and deviations $(\triangle P / P \%)$; isobaric data, with number of temperatures $\left(N_{T}\right)$ and deviations $(\Delta T / T \%)$; vapor phase composition data, with number of points $\left(N_{y}\right)$ and deviations $(\Delta y / y \%)$.

type* : salt molality $(m)$, mole fraction of salt $(x)$

\begin{tabular}{|c|c|c|c|c|c|c|c|c|c|c|c|}
\hline Components & $T_{\min }-T_{\max }$ & $P_{\min }-P_{\max }$ & $m_{\min }-m_{\max }$ & type & Ref. & $N_{P}$ & $\triangle P / P \%$ & $N_{T}$ & $\Delta T / T \%$ & $N_{y}$ & $\Delta y / y \%$ \\
\hline \multicolumn{12}{|l|}{ Methane } \\
\hline$-\mathrm{MgCl}_{2}$ & 298 & $24-52$ & $0-2$ & $m$ & {$[62]$} & 9 & 9.90 & - & - & - & - \\
\hline$-\mathrm{CaCl}_{2}$ & 298 & $24-52$ & $0-2$ & $m$ & [62] & 9 & 10.48 & - & - & - & - \\
\hline$-\mathrm{KCl}$ & $313-373$ & $0-98$ & $1-4$ & $m$ & [66] & 84 & 9.70 & - & - & - & - \\
\hline$-\mathrm{LiCl}$ & $313-353$ & $0-75$ & $2-5$ & $m$ & [66] & 45 & 12.69 & - & - & - & - \\
\hline$-\mathrm{KBr}$ & $313-353$ & $0-80$ & $2-5$ & $m$ & [66] & 35 & 6.30 & - & - & - & - \\
\hline$-\mathrm{LiBr}$ & $313-353$ & $0-100$ & $1-5$ & $m$ & {$[66]$} & 45 & 3.71 & - & - & - & - \\
\hline \multicolumn{12}{|l|}{ Carbon dioxide } \\
\hline$-\mathrm{CaCl}_{2}$ & $298-423$ & $16-712$ & $0-4$ & $m$ & {$[48,105,108]$} & 62 & 12.16 & - & - & - & - \\
\hline$-\mathrm{KCl}$ & $313-423$ & $0-182$ & $0-4$ & $m$ & {$[66,75]$} & 126 & 14.88 & - & - & 30 & 0.66 \\
\hline \multicolumn{12}{|l|}{ Ethanol } \\
\hline - $\mathrm{LiCl}$ & $298-318$ & $0-1$ & $0-1$ & $m$ & [68] & 55 & 8.36 & - & - & - & - \\
\hline$-\mathrm{LiBr}$ & $298-318$ & $0-1$ & $0-1$ & $m$ & [68] & 55 & 4.70 & - & - & - & - \\
\hline \multicolumn{12}{|l|}{ 1-Propanol } \\
\hline$-\mathrm{KBr}$ & $360-364$ & 1 & $0-7$ & $m$ & [69] & - & - & 36 & 0.46 & 36 & 13.06 \\
\hline
\end{tabular}




\section{Table D}

System carbon dioxide $^{(1)}$-methanol ${ }^{(2)}$-water ${ }^{(3)}$-sodium chloride. Detailed example of VLE calculations at a given temperature and salt concentration : $T=$ $313.66 \mathrm{~K}, \rho=0.049, m_{s}=1.74 \mathrm{~mol} \cdot \mathrm{kg}^{-1}$; ions: $\mathrm{Na}^{+(4)}$ and $\mathrm{Cl}^{-(5)}$.

\section{Pure compounds}

$$
\begin{aligned}
a(1) / R T\left(\mathrm{~cm}^{3}\right) & =148.636480 \\
b(1)\left(\mathrm{cm}^{3}\right) & =26.6538026 \\
\mathcal{E}_{r}(1) & =1.500 \\
\Gamma(1,2) / R T & =0.31205593 \\
\Gamma(2,1) / R T & =0.18645135 \\
\Gamma(2,3) / R T & =0.30611973 \\
\Gamma(3,2) / R T & =0.13346754
\end{aligned}
$$

$$
\begin{aligned}
(2) & =613.703444 \\
(2) & =40.9522246 \\
(2) & =29.783 \\
(1,3) & =0.88293962 \\
(3,1) & =0.95808933 \\
(2,4) & =1.05288347 \\
(4,2) & =1.05256404
\end{aligned}
$$

(3) $=363.912384$

(3) $=18.9715643$

(3) $=72.214$

$(1,4)=2.52222675$

$(1,5)=2.07507177$

$(4,1)=2.62021530$

$(5,1)=2.47509435$

$(2,5)=1.05288347$

$(5,2)=1.05256404$

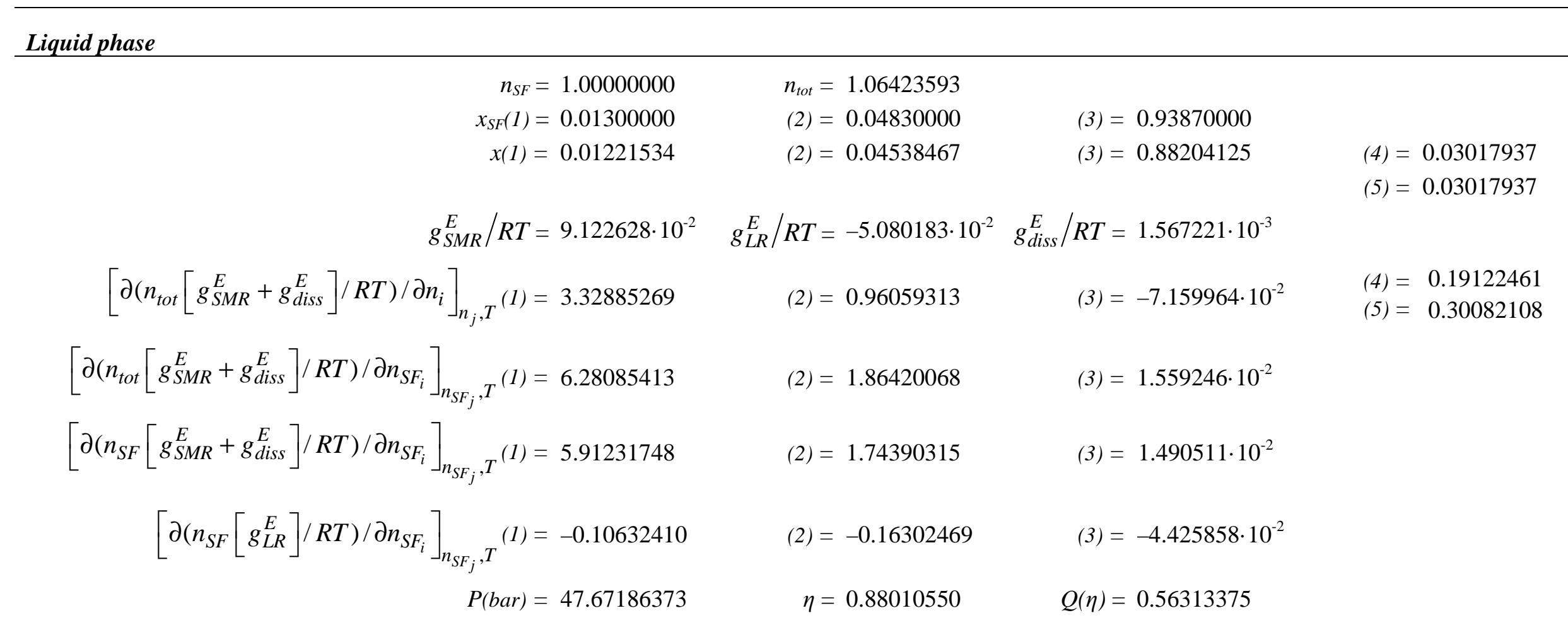




$$
\begin{aligned}
& g_{E o S}^{E} /(0.53 R T)=7.922957 \cdot 10^{-2} \quad \alpha=18.73321705 \quad Z=4.181647 \cdot 10^{-2} \\
& \ln \varphi(1)=4.10319455 \quad(2)=-4.28360608 \quad(3)=-6.44795382 \\
& \varphi(1) x_{S F}(1)=0.78693363 \quad(2)=6.661939 \cdot 10^{-4} \quad \text { (3) }=1.486675 \cdot 10^{-3}
\end{aligned}
$$

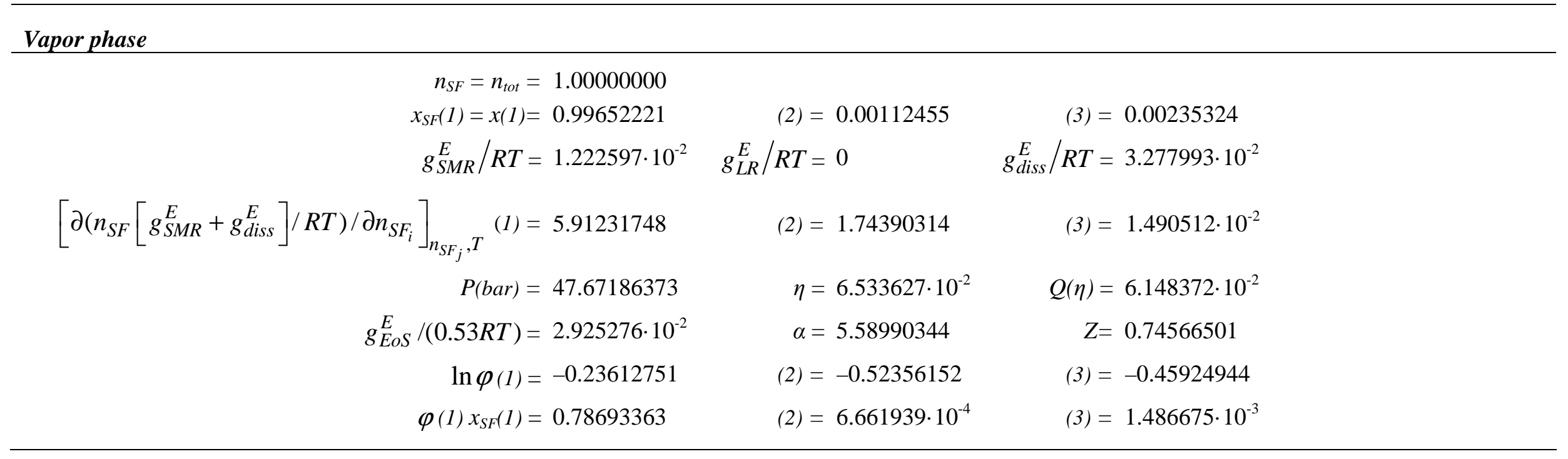



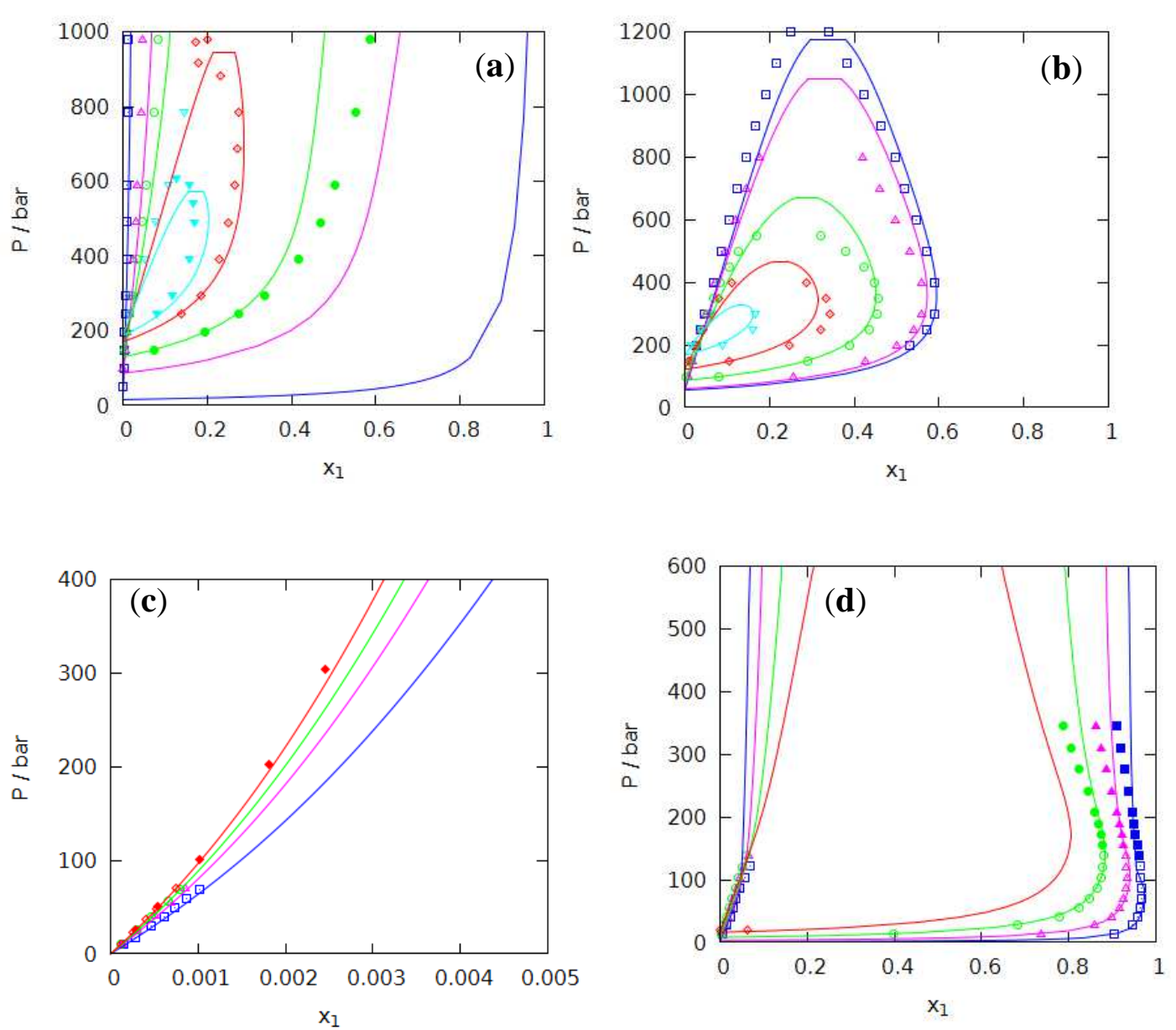

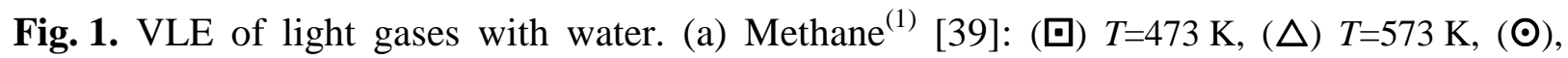
$T=603 \mathrm{~K},(\diamond) T=625 \mathrm{~K},(\nabla),(\boldsymbol{\nabla}) T=633 \mathrm{~K}$. (b) Carbon dioxide ${ }^{(1)}[40]:(\square) T=543 \mathrm{~K},(\triangle) T=548 \mathrm{~K},(\odot)$ $T=573 \mathrm{~K},(\diamond) T=598 \mathrm{~K},(\nabla) T=623 \mathrm{~K}$. (c) Nitrogen ${ }^{(1)}$ : (四) $T=278 \mathrm{~K}[41],(\triangle) T=288 \mathrm{~K}[41]$, (๑)

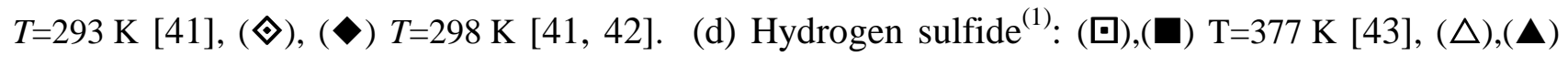

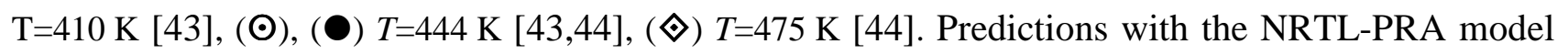
(- colors correspond to symbols).
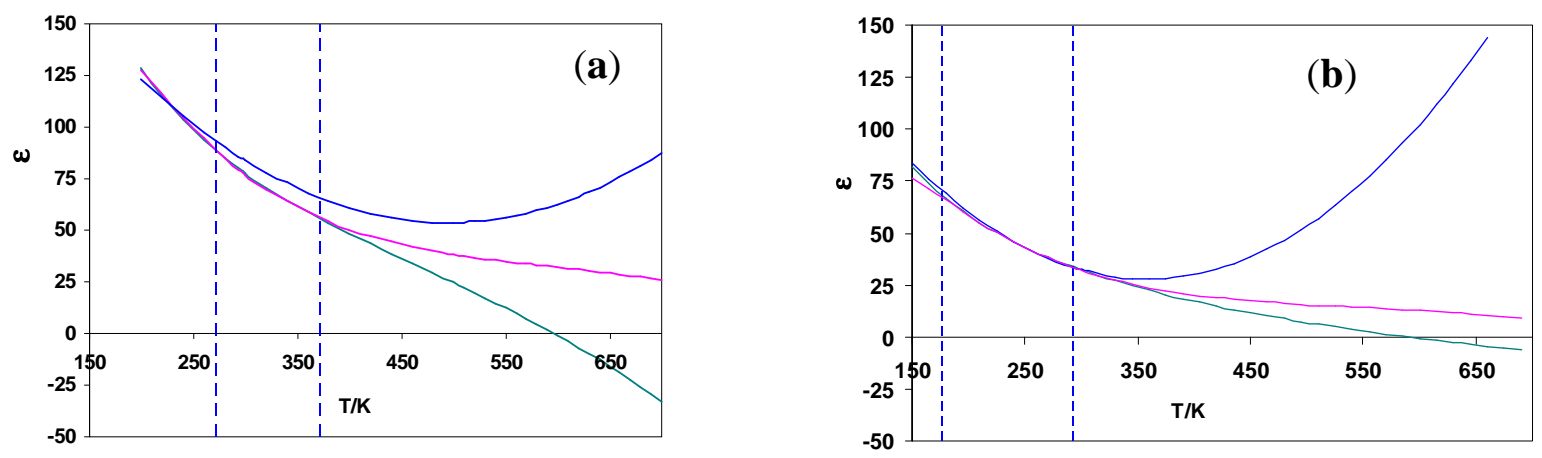

Fig. 2. Relative permittivity $\varepsilon_{r}$ with respect to temperature: (a) $\mathrm{H}_{2} \mathrm{O}$ and (b) methanol. Calculations: ( - ) this work, ( - ) literature (a) [26], (b) [27], ( - ) CRC tables [28]. Limit of the experimental domain $(---)$ [28]. 

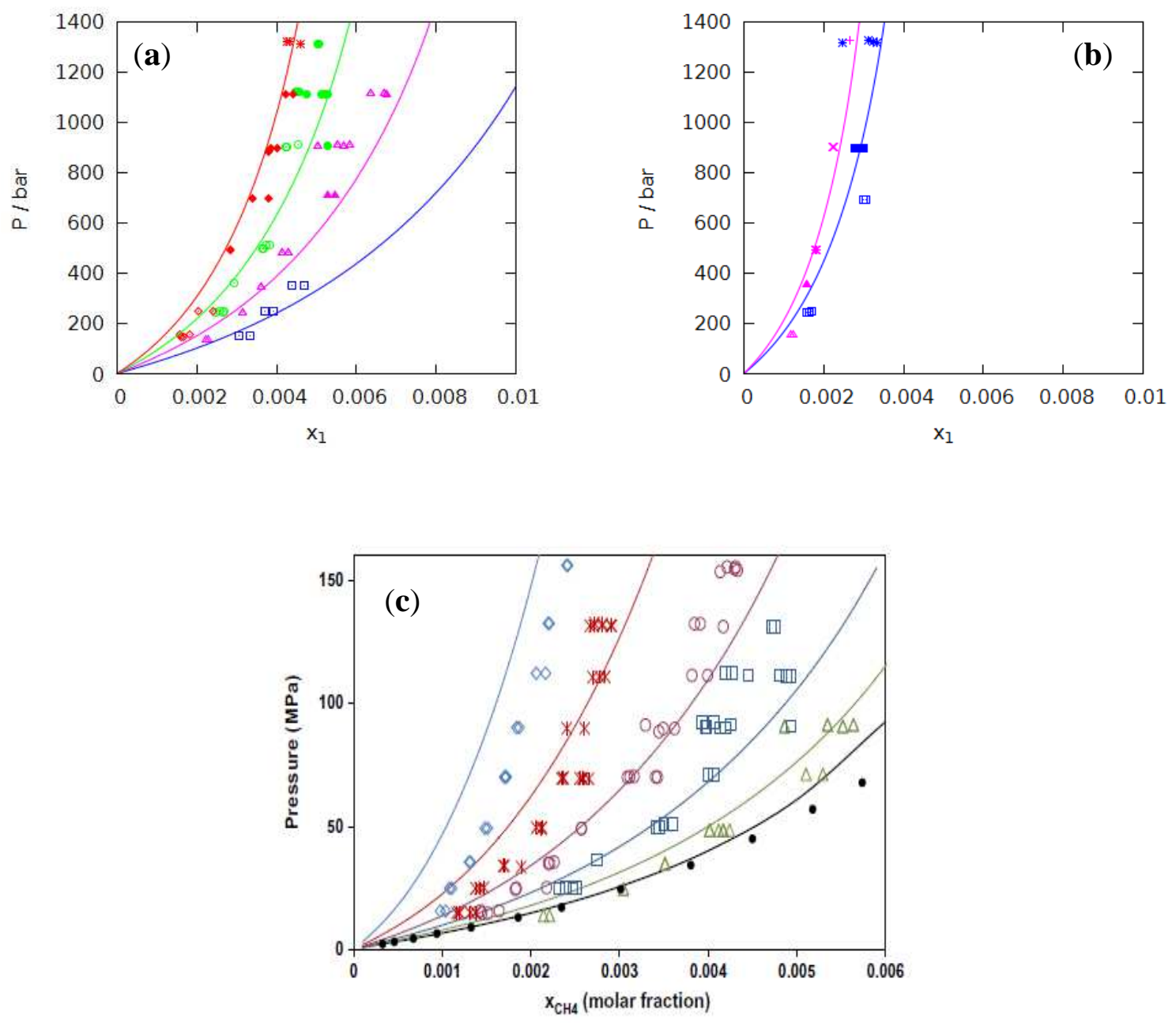

Fig. 3. VLE of methane ${ }^{(1)}-$ water $^{(2)}$ with sodium chloride [45] at $408 \mathrm{~K}$ for various molalities $m_{0}$. (a)

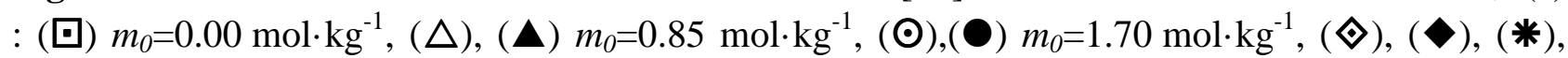
$m_{0}=2.50 \mathrm{~mol} \cdot \mathrm{kg}^{-1}$. (b): (四), (罗), (*) $m_{0}=3.40 \mathrm{~mol} \cdot \mathrm{kg}^{-1},(\triangle),(\boldsymbol{\Delta}),(*),(\mathbf{X}),(+) m_{0}=4.20 \mathrm{~mol} \cdot \mathrm{kg}^{-}$ 1 . Predictions with the NRTL-PRA model (— colors correspond to symbols). (c): eCPA representation [3]. 

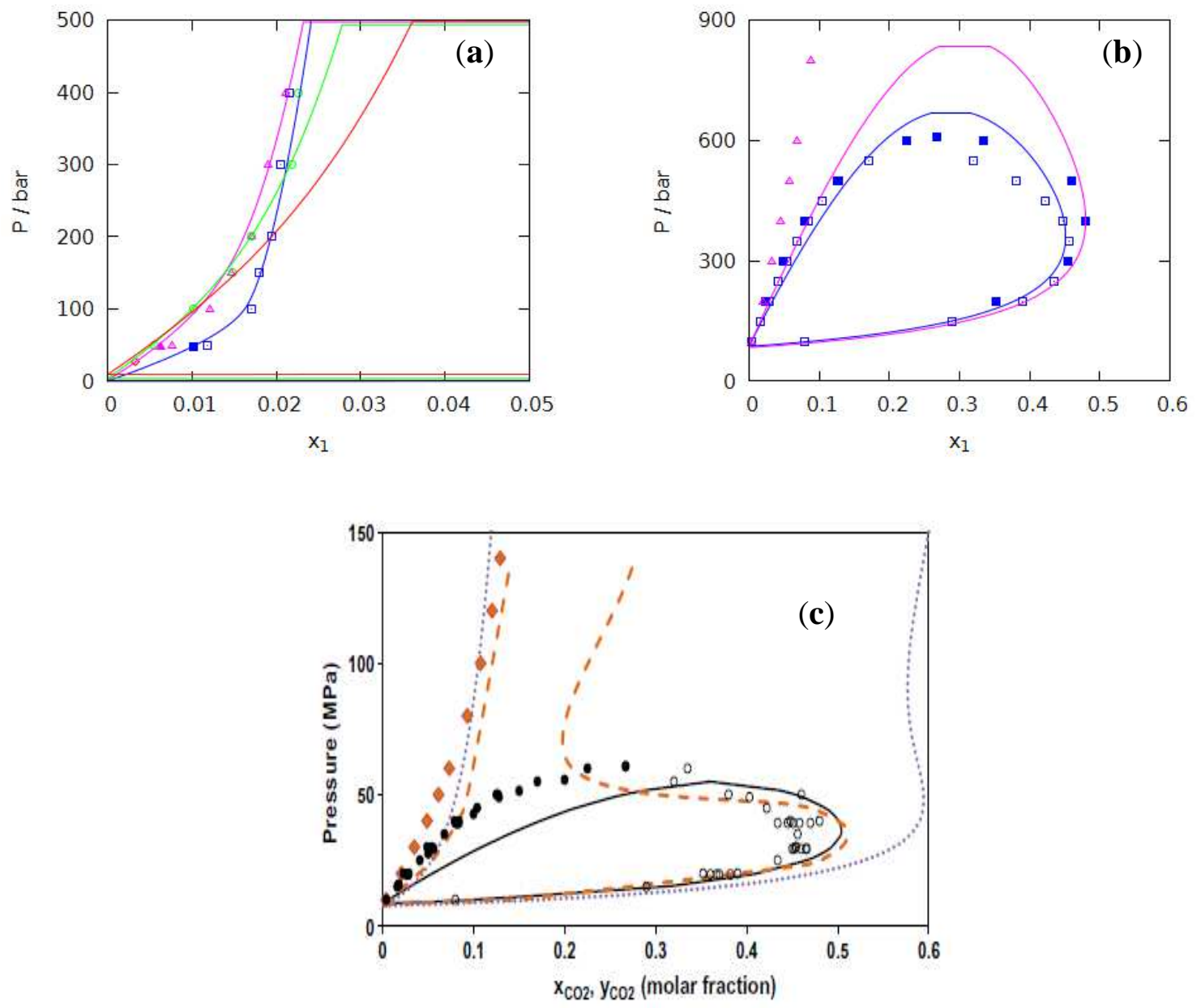

Fig. 4. VLE of carbon dioxide ${ }^{(1)}-$ water $^{(2)}$ with sodium chloride. (a) $\mathrm{NaCl}$ molality $m_{0}=1.00 \mathrm{~mol} \cdot \mathrm{kg}^{-1}$

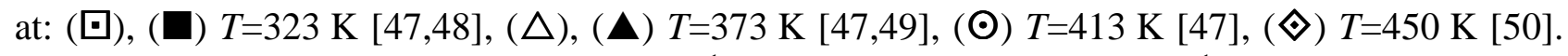
(b) $T=572 \mathrm{~K}$ for: (四), (品 $m_{0}=0.00 \mathrm{~mol} \cdot \mathrm{kg}^{-1}[40,50],(\triangle) m_{0}=1.03 \mathrm{~mol} \cdot \mathrm{kg}^{-1}$ [40]. Predictions with the NRTL-PRA model (— colors correspond to symbols).

(c): eCPA representation [3]. 

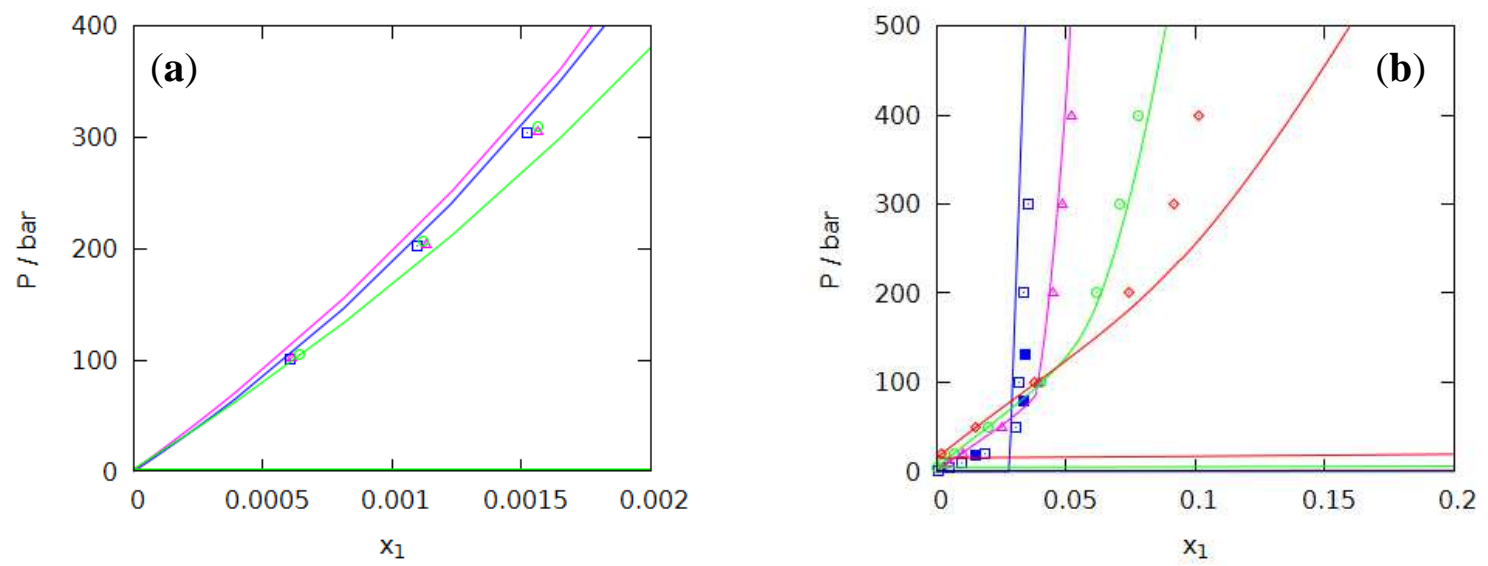

Fig. 5. VLE of (a) nitrogen ${ }^{(1)}-$ water $^{(2)}$ and (b) hydrogen sulfide ${ }^{(1)}-$ water $^{(2)}$ with sodium chloride. $\mathrm{NaCl}$ molality $m_{0}=1.00 \mathrm{~mol} \cdot \mathrm{kg}^{-1}$. (a) [51]: (四) $T=325 \mathrm{~K},(\triangle) T=376 \mathrm{~K}$, (๑) $T=399 \mathrm{~K}$. (b): (回), (ם) $T=323 \mathrm{~K}[52,43],(\triangle) T=373 \mathrm{~K}[52]$, (๑) $T=423 \mathrm{~K}[52],(\diamond) T=473 \mathrm{~K}$ [52]. Calculations with the NRTL-PRA model (— colors correspond to symbols).
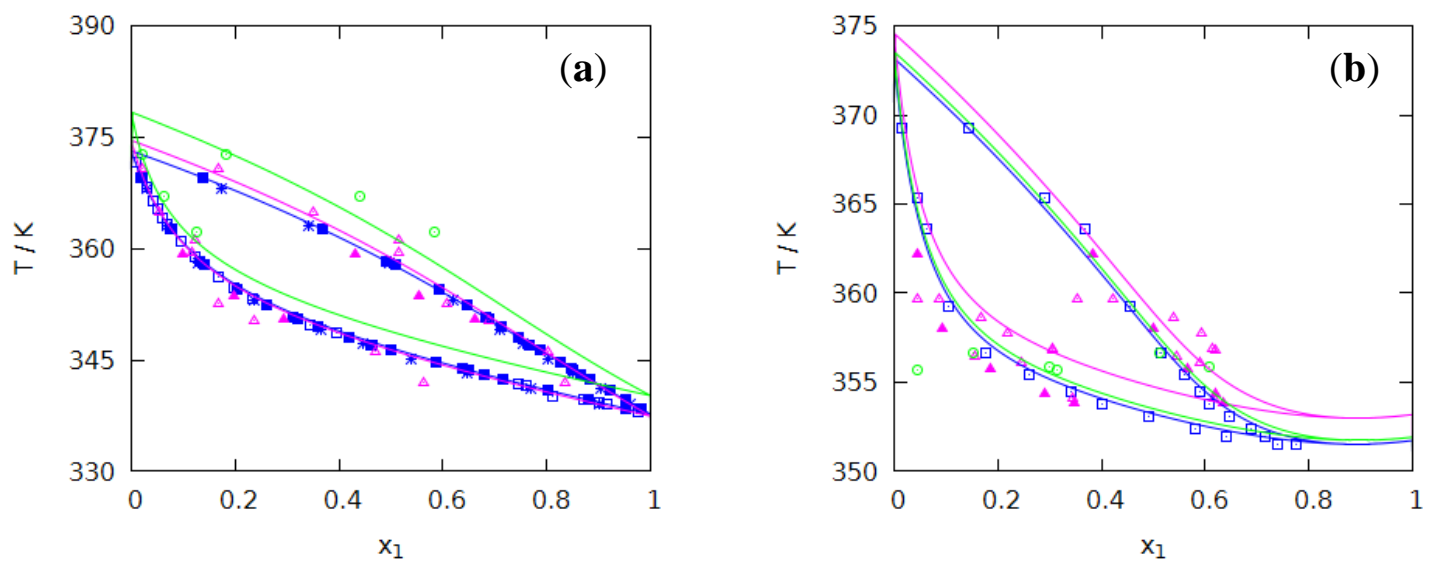

Fig. 6. VLE of (a) methanol ${ }^{(1)}-$ water $^{(2)}$ and (b) ethanol ${ }^{(1)}-$ water $^{(2)}$ with sodium chloride at 1.01 bar

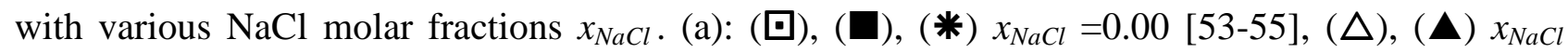

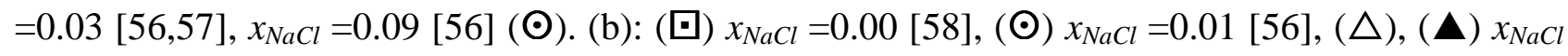
$=0.03$ [56,57]. Calculations with the NRTL-PRA model (— colors correspond to symbols). 

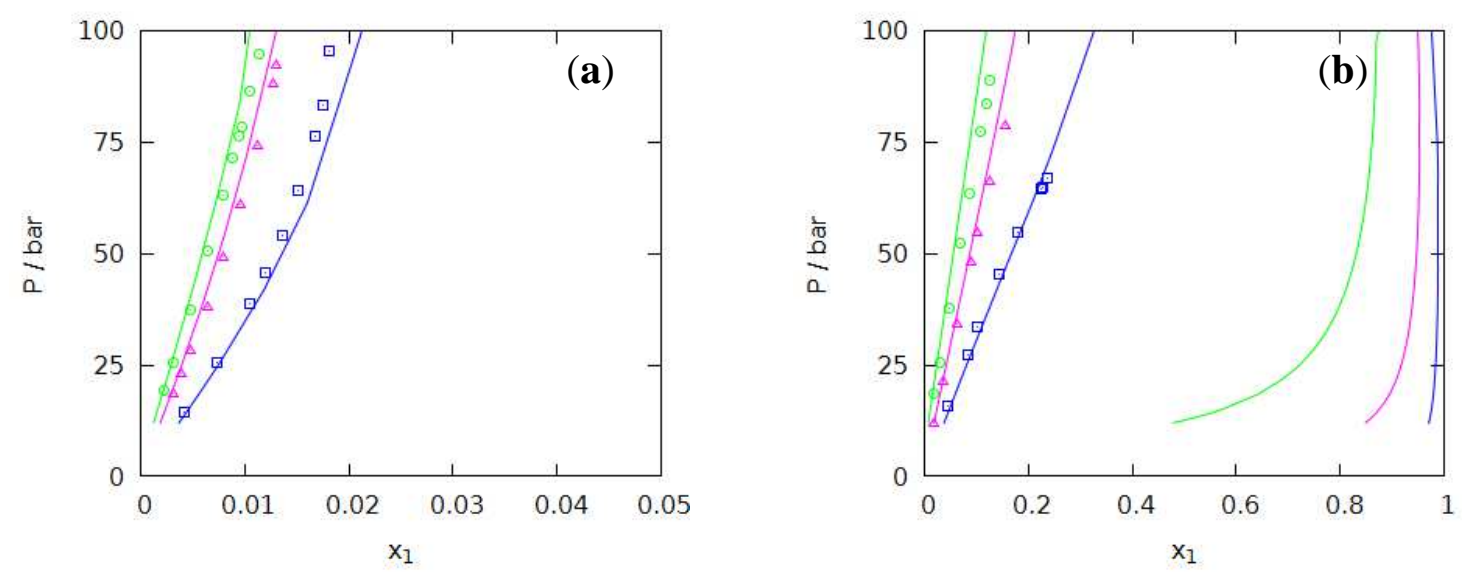

Fig. 7. VLE of carbon dioxide ${ }^{(1)}-$ methanol $^{(2)}-$ water $^{(3)}$ with sodium chloride. Data of Pérez-Salado Kamps et al. [33] at: (回) $T=314 \mathrm{~K},(\triangle) T=354 \mathrm{~K}$, (๑) $T=395 \mathrm{~K}$ for various solute-free solvent mixture composition $\rho$ and molalities $m_{s}$. (a) $\rho=0.049, m_{s}=1.74 \mathrm{~mol} \cdot \mathrm{kg}^{-1}$. (b) $\rho=0.750, m_{s}=0.25$ $\mathrm{mol} \cdot \mathrm{kg}^{-1}$. Predictions with the NRTL-PRA model (— colors correspond to symbols).
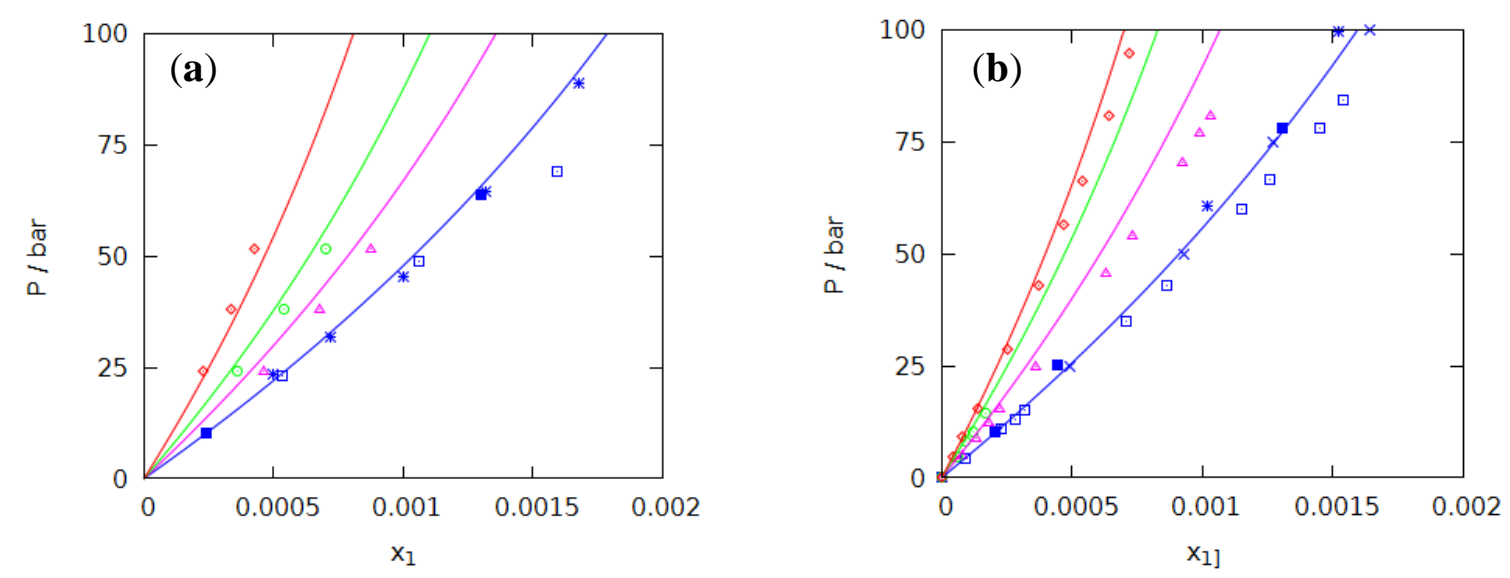

Fig. 8. VLE of methane ${ }^{(1)}-$ water $^{(2)}$ with: (a) $\mathrm{MgCl}_{2}$ and (b) $\mathrm{LiCl}$, for various molalities $m_{0}$. (a)

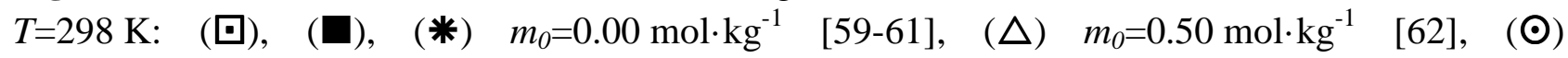

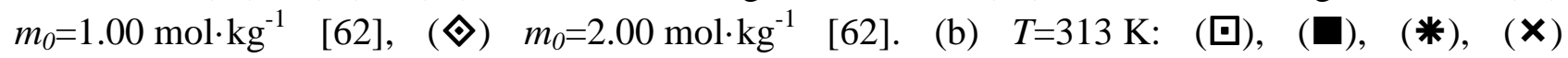
$m_{0}=0.00 \mathrm{~mol} \cdot \mathrm{kg}^{-1}[63,60,59,64],(\triangle) m_{0}=2.49 \mathrm{~mol} \cdot \mathrm{kg}^{-1}[62],(\odot) m_{0}=4.99 \mathrm{~mol} \cdot \mathrm{kg}^{-1}[62],(\diamond)$ $m=7.99 \mathrm{~mol} \cdot \mathrm{kg}^{-1}$ [62]. Calculations with the NRTL-PRA model (- colors correspond to symbols). 

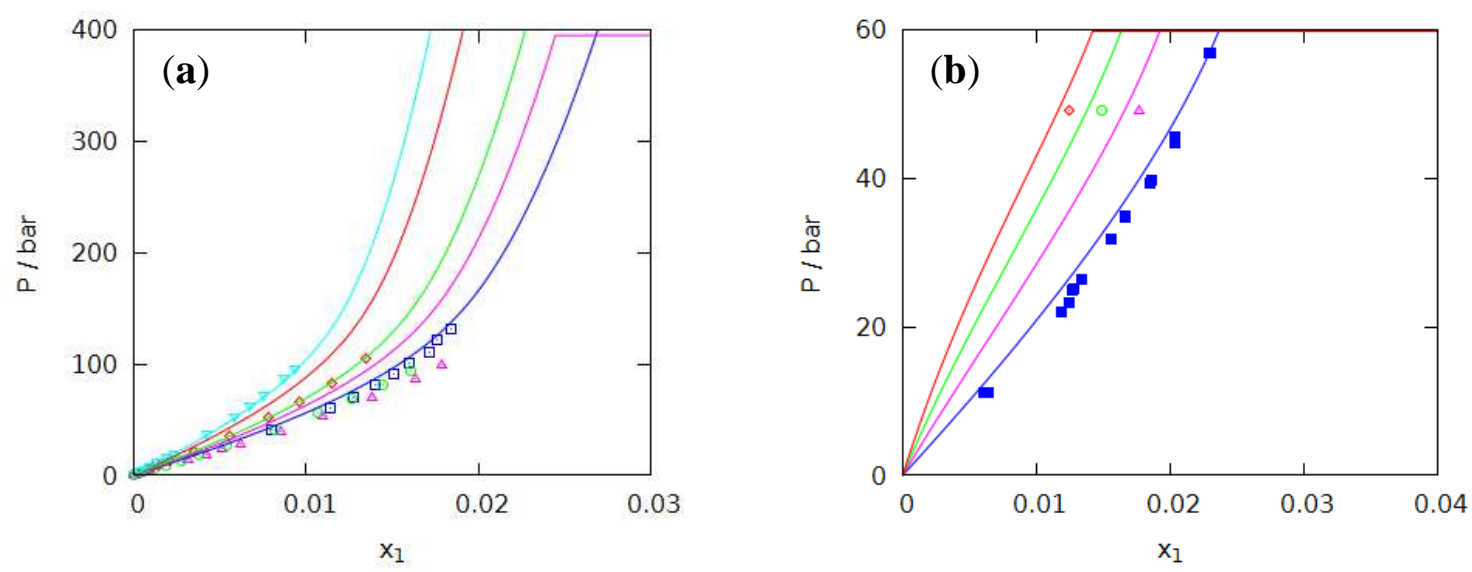

Fig. 9. VLE of carbon dioxide ${ }^{(1)}-$ water $^{(2)}$ with: (a) $\mathrm{KCl}$ and (b) $\mathrm{CaCl}_{2}$ for various molalities $m_{0}$. (a)

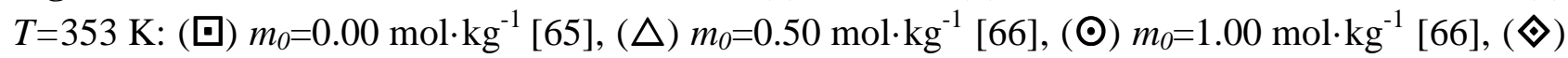

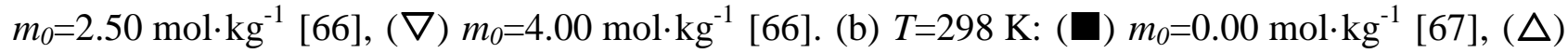
$m_{0}=0.437 \mathrm{~mol} \cdot \mathrm{kg}^{-1}$ [48], (๑) $m_{0}=0.879 \mathrm{~mol} \cdot \mathrm{kg}^{-1}$ [48], $(\diamond) m_{0}=1.349 \mathrm{~mol} \cdot \mathrm{kg}^{-1}$ [48]. Calculations with the NRTL-PRA model (— colors correspond to symbols).
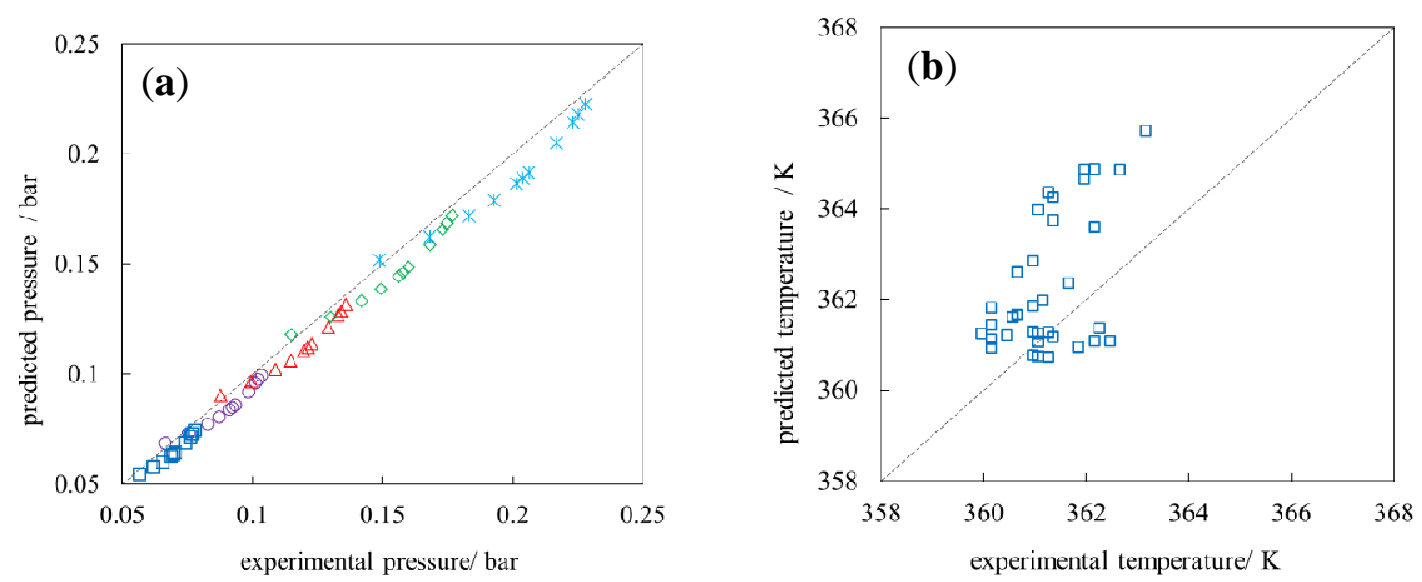

Fig10. VLE of: (a) ethanol ${ }^{(1)}-$ water $^{(2)}$ with $\mathrm{LiBr}$ and (b) 1-propanol ${ }^{(1)}-$ water $^{(2)}$ with $\mathrm{KBr}$, for variable values molalities $m_{0}$. (a) Comparison of predicted pressures with experimental data [68] at: (口) $T=298.15 \mathrm{~K},(\bigcirc) T=303.15 \mathrm{~K},(\triangle) T=308.15 \mathrm{~K},(\diamond) T=313.15 \mathrm{~K}$, (*) $T=318.15 \mathrm{~K}$. (b) Comparison of predicted temperatures with experimental data [69] under $\mathrm{P}=1.01$ bar. Calculations with the NRTL-PRA model. 


\section{Highlights :}

- The NRTL-PRA model is extended to the prediction of VLE in mixtures containing salts.

- Contrary to other cubic EoS, the $g_{\text {res }}^{E}$ only depends on two contributions.

- In equilibrium calculations, ions are supposed to be present only in the liquid phase.

- Many VLE data of light gases and alcohols with $\mathrm{NaCl}$ and other salts were considered.

- The rather satisfactory results thus obtained can be considered significant. 